\title{
Development of high-resolution multi-scale modelling system for simulation of coastal-fluvial urban flooding
}

\author{
Joanne Comer, Agnieszka Indiana Olbert, Stephen Nash, and Michael Hartnett \\ Civil Engineering, College of Engineering and Informatics, Ryan Institute, National University of Ireland, Galway, \\ University Road, Galway, Ireland \\ Correspondence to: Agnieszka Indiana Olbert (indiana.olbert@nuigalway.ie)
}

Received: 5 July 2016 - Discussion started: 18 July 2016

Revised: 16 December 2016 - Accepted: 5 January 2017 - Published: 16 February 2017

\begin{abstract}
Urban developments in coastal zones are often exposed to natural hazards such as flooding. In this research, a state-of-the-art, multi-scale nested flood (MSN_Flood) model is applied to simulate complex coastal-fluvial urban flooding due to combined effects of tides, surges and river discharges. Cork city on Ireland's southwest coast is a study case. The flood modelling system comprises a cascade of four dynamically linked models that resolve the hydrodynamics of Cork Harbour and/or its sub-region at four scales: 90, 30, 6 and $2 \mathrm{~m}$.

Results demonstrate that the internalization of the nested boundary through the use of ghost cells combined with a tailored adaptive interpolation technique creates a highly dynamic moving boundary that permits flooding and drying of the nested boundary. This novel feature of MSN_Flood provides a high degree of choice regarding the location of the boundaries to the nested domain and therefore flexibility in model application. The nested MSN_Flood model through dynamic downscaling facilitates significant improvements in accuracy of model output without incurring the computational expense of high spatial resolution over the entire model domain. The urban flood model provides full characteristics of water levels and flow regimes necessary for flood hazard identification and flood risk assessment.
\end{abstract}

\section{Introduction}

Low-lying developments in coastal zones are exposed to natural hazards such as storm surges, waves, tsunamis and/or high river flows which can lead to significant flooding. Coastal flooding can result in substantial economic and so- cial impacts including loss of life, damage to property and disruption of essential services (Brown et al., 2007).

Coastal flooding results from a rise of sea water level above normal predicted tide level. On the European continental shelf, coastal flooding is associated with storms generated in the Atlantic Ocean that travel through, or in proximity to, the shelf. Storm surges are important consequences of these storms - a temporary water setup resulting from synoptic variation of atmospheric pressure and strong winds blowing towards the shelf, causing water to pile up against the coast. Surge physics is well understood in principle (Ponte, 1994); the mechanism of its propagation on the European continental shelf as a response to meteorological conditions (wind stress and atmospheric pressure signal separate) has been explained by Olbert and Hartnett (2010).

Flood dynamics due to a combination of multiple process drivers such as tides, surges and river inflows and their interactions are extremely difficult to understand using nonmodelling methods (Robins et al., 2011). In recent years the amount of flood modelling work has risen dramatically. Yet the modelling still encounters various problems of which input data such as topography (Mason et al., 2007; Smith, 2002), mesh resolution (Sanders et al., 2010; Fewtrell et al., 2011; Horritt et al., 2006; Yu and Lane, 2006), bottom roughness (Mason et al., 2003; Horritt, 2000) or modelling framework (Hunter et al., 2008) are of greatest challenge. So far, one of the main issues hampering research into coastal flood modelling has been the lack of topographic data of sufficiently high resolution and accuracy along with highly resolvable efficient models. In the past decade, high-resolution topographic data have become more available, with airborne scanning laser altimetry (lidar) technology (Gomes-Pereira 
and Wicherson, 1999) providing high-resolution digital surface maps that can be used as model bathymetry (Marks and Bates, 2000). Although there are still problems with mapping urban areas and considerable post-processing is necessary to extract digital terrain model from digital surface models (Mason at al., 2007), the hydraulic/hydrodynamic models developed using lidar data allow them to numerically propagate surge and tidal waves into coastal areas. Model accuracy and computational cost are still issues to be addressed.

The most common and simple approach to the modelling of coastal flooding in urban areas is to link (externally or dynamically) longitudinal 1-D or latterly averaged 2-D hydraulic models with coastal models (e.g. Formaggia, 2001; Chen, 2007; Brown et al., 2007). Such a setup has two significant drawbacks. Firstly, 1-D/2-D hydraulic models work with the assumption that the lateral variations in velocity magnitudes are small, while in reality many coastal floodplains (e.g. urban areas) contain channels that have a significant influence on the development of inundation by providing routes along which storm surges propagate inland (Bates et al., 2005) and therefore may lead to misrepresentation of localized flooding (Cook and Merwade, 2009; Mark et al., 2004). Secondly, numerical errors may be introduced when linking different models with different dimensions resulting from poor conservation of momentum (Yang et al., 2012). There is evidence of proven difficulty in ensuring that each model interprets the model inputs and boundary conditions in the same way (Hunter et al., 2008; Pender and Neelz, 2010).

These problems may be overcome by application of a single hydrodynamic model to both coastal waters and coastal floodplains. Although such a model would allow smooth transition of the model solution between coastal waters and floodplains, the full solution at scales appropriate for flood inundation would incur a significant computational cost. On one hand, such models need to extend far enough offshore to capture the development and propagation of surge and to resolve the non-linear shallow-water dynamics (interactions between tides, surges and waves) at a resolution that is commensurate with flow features. On the other hand the model needs to include upstream river channels, tidal flats, lowlying land and urban areas which are susceptible to flooding at very fine resolution. This often results in a model setup that requires a large computational domain of which the area of particular interest (such as floodplains here) comprises only a small percentage. For structured grid models such requirements are often cost-prohibitive, and the alternative is to use lower resolution at the expense of accuracy. This means that model discretization is performed at scales well below those achievable with lidar data (the level of individual buildings in the case of urban flooding), meaning the highly resolved lidar data are not being optimally used (McMillian and Brasington, 2007). Some quite successful attempts have been made using unstructured-grid models allowing selective grid refinement (e.g. Yang et al., 2012; Robins et al., 2011); however, the computational demand of these models is high.
A relatively new approach to address this problem in highresolution flood modelling makes use of continuing advances in computational resources through numerical domain decomposition and multi-core architecture runs (Sanders et al., 2010). This method, however, requires substantial computational resources not commonly available yet.

In reality the modelling of coastal flooding (particularly in an urban environment) is a multi-scale problem that requires accurate solution at various scales ranging from coastal sea or estuary scale down to a dense street network of the inundated urban area. In the case of single rectilinear grid models, which are still the most commonly used hydrodynamic models, this spatial-resolution problem may be overcome by grid nesting; this involves embedding higher-resolution grids within a lower-resolution global large-scale grid model. Such a solution allows users to specify high resolution in a subregion of the model domain without incurring the computational expense of fine resolution over the entire domain. Nonetheless, the nested model for simulation of floodplains must be very carefully chosen due to the flooding and drying properties of such zones; most nested models developed to date do not incorporate flooding and drying as they have been developed specifically for large-scale application where this phenomenon is not important (e.g. ROMS; Haidvogel et al., 2008) or, even if they incorporate flooding and drying such as Mike21 (DHI Software, 2001), flooding and drying of open boundaries are prohibited. This problem has been recently resolved in the multi-scale nested flood (MSN_Flood) model of Nash and Hartnett (2010), which allows flooding and drying both within the domain and along boundaries, while maintaining accuracy and computational efficiency. This model is ideally suited for high-resolution modelling of urban flooding and, therefore, has been adopted for further development in this research.

In this context, the authors present in this paper for the first time the application of the state-of-the-art flood model MSN_Flood to complex coastal-fluvial urban flooding in estuary-lying Cork city, which is subject to the combined effects of tides, surges and river discharges. The primary objectives of this paper then are to present the development of this model and to critically examine its capability to forecast/hindcast the urban inundation. It will be demonstrated in this paper that through the novel solution to the nested boundary, the so-called moving boundary, the nested model allows simulation of the propagation of open-sea conditions up to the tidally active river upstream as well as rural and urban floodplains in a computationally efficient manner without compromising model accuracy or stability.

The modelling framework proposed in this research comprises a cascade of multiple nested models that dynamically downscale large-scale, coastal sea processes to the fineresolution scale of urban environments. MSN_Flood was applied to the area of Cork city, Ireland, and its coastal floodplains; Cork city is frequently subject to coastal-fluvial flooding. An extreme flood event of November 2009 that resulted 
in approximately EUR 100 million of flood damage in the city and its surrounds was chosen as a test case. The main features of this accurate and efficient hydraulic modelling are illustrated through the Cork city application. In particular, wetting and drying routine, computational efficiency, and accuracy of simulated water elevations and velocity fields are subject to in-depth analysis in this research.

This paper is organized as follows: Sect. 1 describes the motivation for this research and related work; Sect. 2 describes modelling, model setup and datasets; Sect. 3 presents and compares numerical model results with observed datasets; Sect. 4 discusses the advantages the MSN_Flood modelling system; and finally Sect. 5 contains conclusions from the research.

\section{Methodology}

In this section a modelling system for coastal flood inundation is described along with the datasets and model setup for the Cork city flood event.

\subsection{Modelling framework}

Many flood inundation events in urban environments have been modelled using simple hydraulic models, such as HECRAS (Pappenberger et al., 2005) or LISFLOOD-FP (Bates and De Roo, 2000), incapable of simulating flood water velocities required for accurate determination of flood wave propagation routes and assessment of risks associated with a certain flood flow magnitude. A more realistic analysis can be achieved using a hydrodynamic model that resolves both the continuity and momentum equations throughout the entire domain.

Here, the MSN_Flood model was applied to Cork city using a cascade of four nested grids to describe hydrodynamics at various scales with particular interest in water elevations and velocity fields over the inundated area. This nested model facilitates the refinement of spatial resolution in Cork Harbour from $90 \mathrm{~m}$ at the outer reaches of the harbour down to $2 \mathrm{~m}$ in the streets of Cork city.

\subsection{Hydrodynamics}

MSN_Flood is a two-dimensional, depth-averaged, finitedifference model, and its solver is based on the alternate direction implicit (ADI) solver developed by Falconer (1984) (Lin and Falconer, 1997; Nash and Hartnett, 2010). The governing differential equations used in the model to determine the water elevation and depth-integrated velocity fields in the horizontal plane are based on integrating the threedimensional continuity and Navier-Stokes equations over the water column depth. Assuming vertical accelerations are negligible compared with gravity and that the Reynolds stresses in the vertical plane can be represented by a Boussinesq approximation, then the depth-integrated continuity and $x$ direction momentum equations are of the following form (Falconer and Chen, 1991): continuity equation,

$$
\frac{\partial \zeta}{\partial t}+\frac{\partial q_{x}}{\partial x}+\frac{\partial q_{y}}{\partial y}=0
$$

momentum equation in $x$ direction,

$$
\begin{aligned}
\frac{\partial q_{x}}{\partial t} & +\beta\left[\frac{\partial U q_{x}}{\partial x}+\frac{\partial U q_{y}}{\partial y}\right]=f q_{y}-g H \frac{\partial \zeta}{\partial x} \\
& +\frac{\rho_{\mathrm{a}} C^{*} W_{x}\left(W_{x}^{2}+W_{y}^{2}\right)^{1 / 2}}{\rho}-\frac{g U\left(U^{2}+V^{2}\right)^{1 / 2}}{C^{2}} \\
& +2 \frac{\partial}{\partial x}\left[\varepsilon H \frac{\partial U}{\partial x}\right]+\frac{\partial}{\partial y}\left[\varepsilon H\left[\frac{\partial U}{\partial y}+\frac{\partial V}{\partial x}\right]\right],
\end{aligned}
$$

where $t$ is time; $U$ and $V$ are depth-averaged velocity components in the $x$ and $y$ directions, respectively; $q_{x}$ and $q_{y}$ are depth-integrated volumetric flux components in the $x$ and $y$ directions $\left(q_{x}=U H ; q_{y}=V H\right) ; H$ is total water depth; $\beta$ is a momentum correction factor for non-uniform vertical velocity profile; $f$ is a Coriolis parameter $(=2 \omega \operatorname{Sin} \phi$, where $\omega$ is the angular velocity of the earth's rotation and $\phi$ is geographical latitude); $g$ is gravitational acceleration; $\rho_{\mathrm{a}}$ and $r$ are air and fluid densities, respectively; $C^{*}$ is an air-water interfacial resistance coefficient; $W_{x}$ and $W_{y}$ are wind velocity components in $x$ and $y$ directions, respectively; $C$ is a Chezy bed roughness coefficient; and $\varepsilon$ is depth mean eddy viscosity.

\subsection{Nesting structure and procedure}

MSN_Flood consists of one outer coarse grid, called the parent grid (PG), into which one or more inner fine grids (child grids, CGs) are one-way nested. The model also enables multiple nesting such that a child grid may also be a parent to another child. In this way, multi-scale nesting can be specified enabling high spatial resolution in areas of interest. PG and CG models are dynamically coupled and synchronous. An overview of the nesting procedure is schematically presented in Fig. 1. As can be seen, the time integration is a bottom-up approach where PG can be advanced in time only when all of its children are integrated to the parent current time. The ADI solution technique to solve the governing continuity and momentum equations requires the sub-division of each time step into two half-time-steps. The nesting procedure, for each nesting level, is summarized in the following 5 steps:

1. integrate outermost parent grid one time step $\left(t+\Delta t_{\mathrm{p}}\right)$;

2. extract parent grid data and interpolate (spatially and temporally) along child grid boundary to next time levels of child grid $\left(t+1 / 2 \Delta t_{\mathrm{c}}\right)$ and $\left(t+\Delta t_{\mathrm{c}}\right)$;

3. integrate child grid 1 time step $\left(t+\Delta t_{\mathrm{c}}\right)$;

4. repeat steps 2 and 3 so that the child grid is synchronized to the current time step of parent grid $\left(t+\Delta t_{\mathrm{p}}\right)$; 


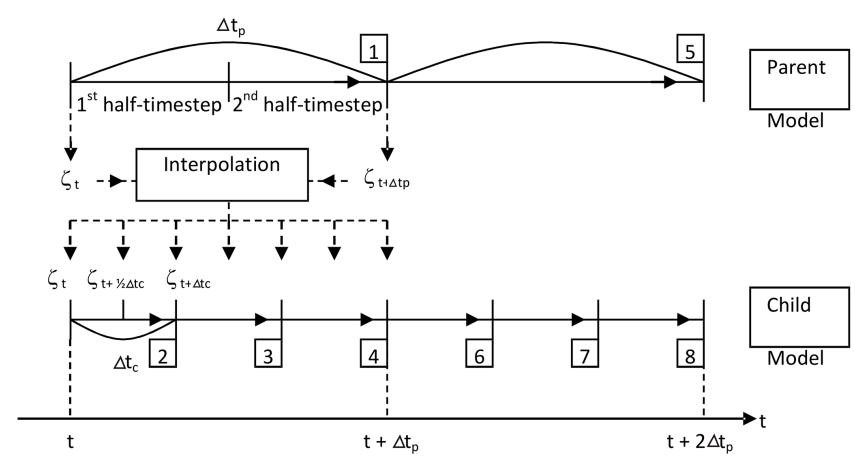

Figure 1. The nesting procedure for a single level of nesting and one variable only - water surface elevation, $\zeta$.

\section{5. return to step 1 and continue.}

The nesting procedure is similar in principle to other nested models (Holt et al., 2009; Korres and Lascaratos, 2003; Nittis et al., 2006), but the uniqueness of MSN_Flood is a novel approach to boundary formulation through an incorporation of ghost cells (GCs) in a manner that the nested boundary operates as an internal boundary. GCs are specified adjacent to nested boundaries so that the boundary configuration consist of two rows/columns of CG cells: internal boundary cells and the adjacent exterior ghost cells. A schematic of the general configuration of the nested boundary is shown in Fig. 2. In this internal boundary approach, PG boundary data are specified to both the ghost cells outside the CG domain and to the internal boundary cells, allowing the governing equations of motion at the internal boundary grid cells to be formulated and solved in the same way as interior grid cells. This enables accurate specification and conservation of incoming fluxes of mass and momentum along the boundaries of the nests. To demonstrate benefits of this approach, the finite-difference formulation for the advective term in the momentum equation, which is key to momentum conservation, at boundary cells becomes

$$
\begin{aligned}
& \frac{\partial U q_{x}}{\partial x}=\left[\frac{[U(x+\Delta x, y)+U(x, y)]}{2} \cdot \frac{\left[q_{x}(x+\Delta x, y)+q_{x}(x, y)\right]}{2}\right. \\
& \left.-\frac{[U(x, y)+U(x-\Delta x, y)]}{2} \cdot \frac{\left[q_{x}(x, y)+q_{x}(x-\Delta x, y)\right]}{2}\right] .
\end{aligned}
$$

For comparison, in a boundary formulation without ghost cells, the derivative $\partial U q_{x} / \partial x$ would be set to 0 as ghost cell grid points $U(x+\Delta x, y)$ or $U(x-\Delta x, y)$ would not exist; therefore momentum would not be conserved between parent grid and child grid.

An important feature of the nesting approach in MSN_Flood is the implementation of moving boundaries along the boundary of the nested domains. The flooding and drying routine originally developed by Falconer and Chen (1991) is implemented in MSN_Flood; this boundary formulation allows the model to be applied to areas of intertidal zone or coastal flooding where there is typically a con-

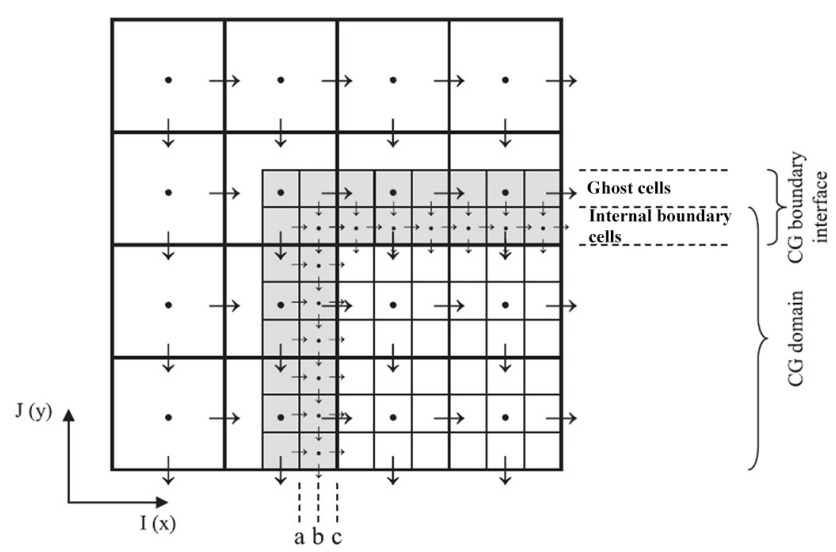

Figure 2. Schematic illustration of the internal boundary configuration for $3: 1$ nesting ratio.

siderable degree of alternate flooding and drying throughout the domain. The flooding and drying routine by Falconer and Chen has been extensively tested in laboratory conditions and natural waterbodies and shown to be stable and robust. However, when the nested boundary was subject to flooding and drying, despite the overall improvement in mass and momentum conservation along the nested boundary, significant errors were found to occur near the boundary in areas of flooding and drying. This problem was overcome by implementation of an adaptive interpolation scheme which uses linear interpolation or zeroth-order interpolation depending on the status (wet or dry) and the configuration of parent grids along the boundary interface. More details of the method can be found in Nash (2010). This adaptive interpolation in combination with ghost cell and internal boundary formulation ensures the stable flooding and drying of boundary cells.

The ghost cell formulation of the boundary was found to significantly reduce boundary formulation errors, one of three error sources in nested models as classified by Nash and Hartnett (2010). Boundary formulation errors arise from simplification of mathematical formulation of the governing equations of motion at open-boundary grid cells. Two other sources of errors at the boundary interface are boundary specification errors and boundary operation errors. While the former errors arise from incorrect boundary data, and can be minimized by locating nested boundary in areas of high PG accuracy, boundary operator errors result from the use of an inadequate interpolation schemes and/or boundary condition for prescribing PG data to the CG boundary and are more challenging to reduce. During the course of model developments various interpolation schemes were tested, including a zeroth-order scheme, a linear scheme, a mass-conserving quadratic scheme and an inverse distance weighted scheme. The linear interpolation was found to be most accurate in both time and space and therefore was implemented in the model (Nash, 2010). With regards to the boundary conditions, three different types of boundary con- 


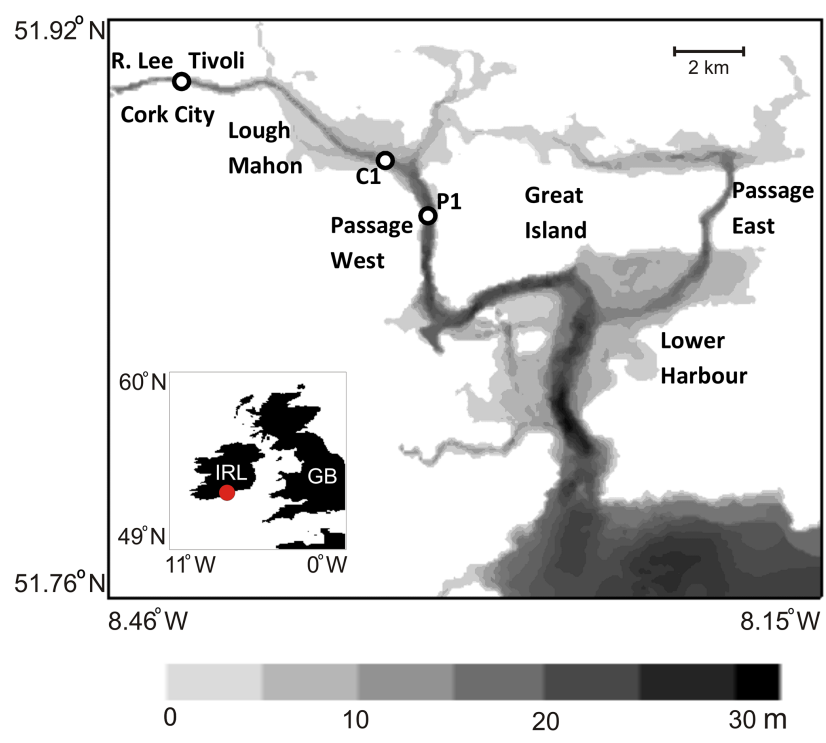

Figure 3. Bathymetry of Cork Harbour (m) with selected locations. Red dot denotes location of Cork Harbour on the coast of Ireland.

ditions were tested, namely Dirichlet condition, flow relaxation condition and radiation condition. Extensive numerical testing showed that the most stable and accurate model solution could be achieved by implementing the Dirichlet boundary condition. Accuracies of various interpolation and boundary condition schemes were analysed and compared in Nash and Hartnett (2014).

Reduction in boundary errors due to the accurate development of boundary operators and more accurate mathematical formulation of the nested boundary yielded significant improvements in conservation of mass and momentum between parent and child grids. This in turn improved model stability at the nested boundary and CG accuracy. These features make MSN_Flood highly applicable to modelling complex coastal flooding events as in the current test case, where the nested boundary is located in the flooding and drying zone, and therefore its length changes dynamically throughout the flooding event. This non-continuous moving boundary feature is the subject of in-depth investigation in this research.

\subsection{Study area description and model setup}

Cork Harbour, in the southwest of Ireland, is a shallow (average depth $8.4 \mathrm{~m}$ ) meso-tidal estuary with typical spring tide ranges of $4.2 \mathrm{~m}$. Return levels of tides for 2- and 100-year return periods are 4.45 and $4.52 \mathrm{~m}$ above chart datum, respectively, while surge residual return levels for the same return periods are 0.56 and $0.85 \mathrm{~m}$, respectively (Olbert et al., 2013). The Cork Harbour domain is presented in Fig. 3. Cork city is a densely populated urban area of approximately 120000 people, located at the mouth of the River Lee, which drains into Cork Harbour. Tidal components of flooding in Cork city are due to combinations of high astronomical tides

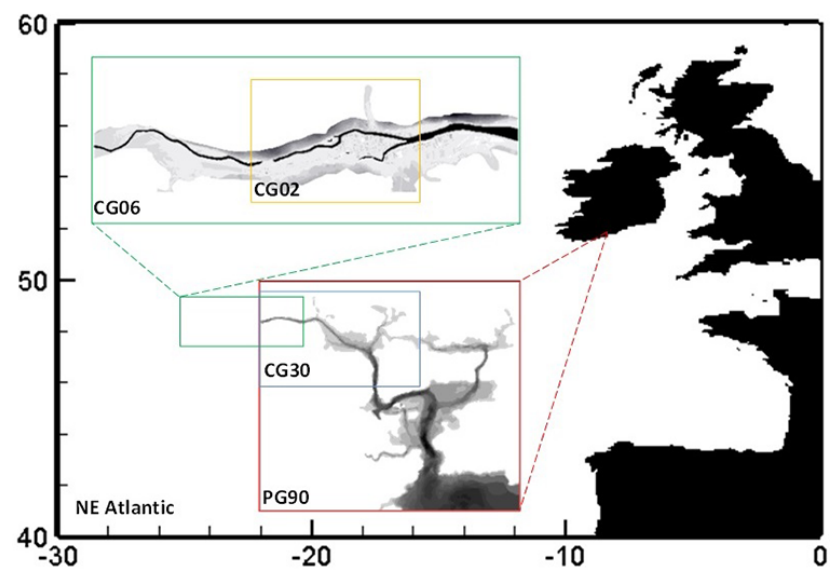

Figure 4. Four-level nesting structure of Cork Harbour and Cork city nested models.

and storm surges generated in the open ocean and propagating into the harbour and throughout the city streets. The River Lee corridor flows from west to east along the post-glacial valley into the Lee proper, through Cork city, into Lough Mahon and Cork Harbour, and south into the Atlantic Ocean. In the city, the River Lee bifurcates into the north and south channels around the Mardyke area and merges again at the eastern edge of the city. The river flows for 2- and 100-year return periods are 208.6 and $307.7 \mathrm{~m}^{3} \mathrm{~s}^{-1}$, respectively (Halcrow, 2008). Sea water intrusion up the river is bounded by a weir located $8 \mathrm{~km}$ upstream from the river mouth.

MSN_Flood was used in this research to develop a coastalurban hydraulic model capable of simulating fluvial and coastal flooding in Cork city. The model grid needs to be set up to include not only river channel and urban floodplains but also offshore waters necessary to resolve the non-linear hydrodynamics. The Cork Harbour/city model is therefore configured as a four-level cascade of dynamically linked nested grids that resolve the hydrodynamics of the region at spatial scales of 90, 30, 6 and $2 \mathrm{~m}$. Each coarser grid provides boundary conditions to the next-finer grid; i.e. the $90 \mathrm{~m}$ grid provides boundary conditions to the $30 \mathrm{~m}$ grid, the $30 \mathrm{~m}$ grid provides boundary conditions to the $6 \mathrm{~m}$ grid etc. Figure $4 \mathrm{a}$ illustrates the extent of each grid and the nesting structure, while Fig. $4 \mathrm{~b}$ shows details of the high-resolution $6 \mathrm{~m}$ grid and the $2 \mathrm{~m}$ urban flood grid.

The parent grid (PG90) representing the full domain of Cork Harbour was resolved at a grid spacing of $90 \mathrm{~m}$. At $3: 1$ nesting ratio, the first child grid (CG30), completely embedded within the parent model domain, has a grid spacing of $30 \mathrm{~m}$. The CG30 model provides boundary conditions to a $6 \mathrm{~m}$ grid (CG06) at a 5:1 nesting ratio. The domains of CG30 and CG06 models only partially overlap. Water elevations computed on CG30 are passed to the eastern boundary of CG06, while River Lee flow data are specified at the western boundary of CG06. Finally, the ultra-high-resolution $2 \mathrm{~m}$ 
Table 1. Configuration of nested models.

\begin{tabular}{lrrrc}
\hline Model & $\begin{array}{r}\text { Grid size } \\
(\mathrm{m})\end{array}$ & $\begin{array}{r}\text { Time step } \\
(\mathrm{s})\end{array}$ & $\begin{array}{r}\text { Parent } \\
\text { model }\end{array}$ & $\begin{array}{c}\text { Parent-to-model } \\
\text { grid ratio }\end{array}$ \\
\hline Parent grid (PG90) & 90 & 18 & - & $1: 1$ \\
Single grid (SG30) & 30 & 6 & PG90 & $1: 1$ \\
Child grid 1 (CG30) & 30 & 6 & PG90 & $3: 1$ \\
Child grid 2 (CG06) & 6 & 0.6 & CG30 & $5: 1$ \\
Child grid 3 (CG02) & 2 & 0.2 & CG06 & $3: 1$ \\
Single grid (SG02) & 2 & 0.2 & CG06 & $1: 1$ \\
\hline
\end{tabular}

child grid (CG02) is entirely embedded within CG06 and is used to simulate urban flooding of Cork city. The nesting ratios of $3: 1$ and $5: 1$ used in this setup are in line with nesting ratios used in other studies (e.g. Spall and Holland, 1991). Configurations of the nested models are summarized in Table 1.

Open-boundary conditions to the MSN_Flood parent grid, PG90, are provided as total water elevations containing tidal and surge signals extracted from an ocean model of the eastern North Atlantic (Olbert and Hartnett, 2010). The surface boundary of the MSN_Flood model is forced by $10 \mathrm{~m}$ wind fields and mean sea level atmospheric pressure obtained from the regional analysis ERA-40 model (Uppala et al., 2005) and operational model first-guess dataset (Simmons et al., 1989). River Lee discharges from gauge station 19011 were provided by the Office of Public Works (OPW), Ireland. Admiralty chart data were used to develop the bathymetric model of Cork Harbour, while high-resolution lidar data provided by the OPW were used to construct the high-resolution urban digital bathymetric model. The channel of the River Lee was included in the model based on cross-sectional survey data also provided by the OPW from an extensive survey of the River Lee catchment in 2008.

\subsection{Verification}

The numerical model skill was assessed by statistically comparing observations and model solutions. Following statistical measures were used:

- root mean square error,

$\operatorname{RMSE}=\left[\frac{1}{N} \sum_{n=1}^{N}\left(Y_{n}-X_{n}\right)^{2}\right]^{1 / 2} ;$

- root mean square difference between model and observations,

RMSdiff $=\left[\frac{1}{N} \sum_{n=1}^{N}\left(Y_{n}\right)^{2}\right]^{1 / 2}-\left[\frac{1}{N} \sum_{n=1}^{N}\left(X_{n}\right)^{2}\right]^{1 / 2} ;$

- centred root mean square difference,

$\operatorname{RMSD}=\left[\frac{1}{N} \sum_{n=1}^{N}\left(\left(Y_{n}-\bar{Y}\right)-\left(X_{n}-\bar{X}\right)\right)^{2}\right]^{1 / 2}$, where $\bar{X}$ and $\bar{Y}$ are the mean values of variables $X$ and $Y$, respectively, for $N$ observations. These measures were also used to inter-compare time series of models of different resolutions.

The spatially comparative measures between various models are based on spatial distribution of errors between fineand coarse-resolution models and are quantified using the following expressions:

- tidally averaged relative errors,

$\mathrm{RE}_{\mathrm{T}}=\frac{\sum_{n=1}^{N}\left|Y_{n}-X_{n}\right|}{\sum_{n=1}^{N}\left|X_{n}\right|} \cdot 100 ;$

- domain-averaged relative error,

$\mathrm{RE}_{D}=\frac{\mathrm{RE}_{\mathrm{T}}}{M} ;$

- absolute error,

$\mathrm{AE}_{\mathrm{T}}=\frac{\sum_{n=1}^{N}\left|Y_{n}-X_{n}\right|}{N} ;$

- relative difference,

$\mathrm{RD}=\frac{\left|X_{n}-Y_{n}\right|}{X_{n}}$,

where $X$ and $Y$ are higher- and coarser-resolution solutions, respectively; $n$ is the output time over a tidal cycle; $N=25$ is the total number of tidal cycles; and $M$ is the number of discrete points in space.

\section{Results}

Showcasing the capability of the multi-level nesting integrated system to accurately simulate the extent and level of urban flooding is central to this research. MSN_Flood has been extensively tested in both laboratory settings (against physical tidal models) and natural open harbours. In this research, a comprehensive validation of the model in a coastal flood application to Cork Harbour and the urban environment of Cork city is presented. Initial evaluation of model accuracy is carried out at each of the four levels of nesting; both modelled water elevations and velocities are compared to available field data. The assessment of the model skill in simulation of urban flooding is carried out for the November 2009 coastal-fluvial flooding of Cork city. In this application, the city streets and open areas are treated as hydraulics channels and plains that can be inundated depending on the tide, surge and fluvial conditions. This is a highly complex hydrodynamic region to model and, therefore, represents a robust test of the model. 


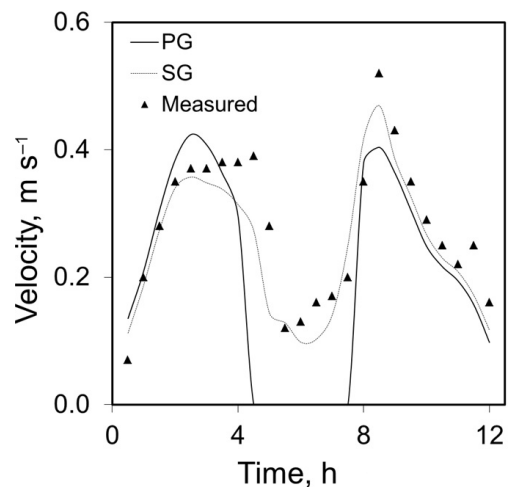

Figure 5. Comparison of computed and measured velocities at point P1in Passage West. Point location shown in Fig. 3.

\subsection{Validation of the nesting procedure}

\subsubsection{PG90 model}

Firstly, the performance of the low-resolution $90 \mathrm{~m}$ parent grid (PG90) model was assessed. Figure 5 compares current velocities simulated by the PG90 model with measured data at Passage West in Cork Harbour over a spring tidal cycle (see Fig. 3 for point P1 location). Results show that, although patterns of currents through flood and ebb conditions are relatively well predicted, the slack water conditions, where velocities are generally smaller, are not reproduced correctly by the PG90 model. A higher-resolution single-grid (SG30) model at $30 \mathrm{~m}$ grid spacing was developed to test the accuracy of PG90. The same domain extents (Fig. 4) and the same physical conditions were specified to the SG30 and PG90 models. As shown in Fig. 5, an increased resolution of the model significantly improves model predictions throughout the tidal cycle and particularly during periods of slack water.

The spatial distribution of PG model error was quantified by calculating the tidally averaged relative errors $R E_{T}$, expressing a percentage error in a PG solution relative to a higher-resolution SG reference solution (Eq. 7). Figure 6 shows the distribution of $\mathrm{RE}_{\mathrm{T}}$ in PG velocities in Cork Harbour; it can be seen that the errors generated by the PG model are well over $30 \%$ at certain locations within the harbour (harbour entrance, along the coastline, narrow channels and estuaries), so increasing the resolution from 90 to $30 \mathrm{~m}$ leads to significant reduction in the error. However, improvements in accuracy due to higher spatial resolution come at a high computational cost, which for the SG model $(80 \mathrm{~min}$ for $50 \mathrm{~h}$ run) is 9 times that of the PG model ( 9 min for $50 \mathrm{~h}$ run). The use of a nested model is then a justifiable and favourable solution.

In the course of extensive validation, the time series of PG90 and SG30 were also inter-compared. Figure 7 shows water elevations and current velocities in Lough Mahon (see Fig. 3 for point $\mathrm{C} 1$ location). Water elevations computed by both models are in very good agreement. In contrast, cur-

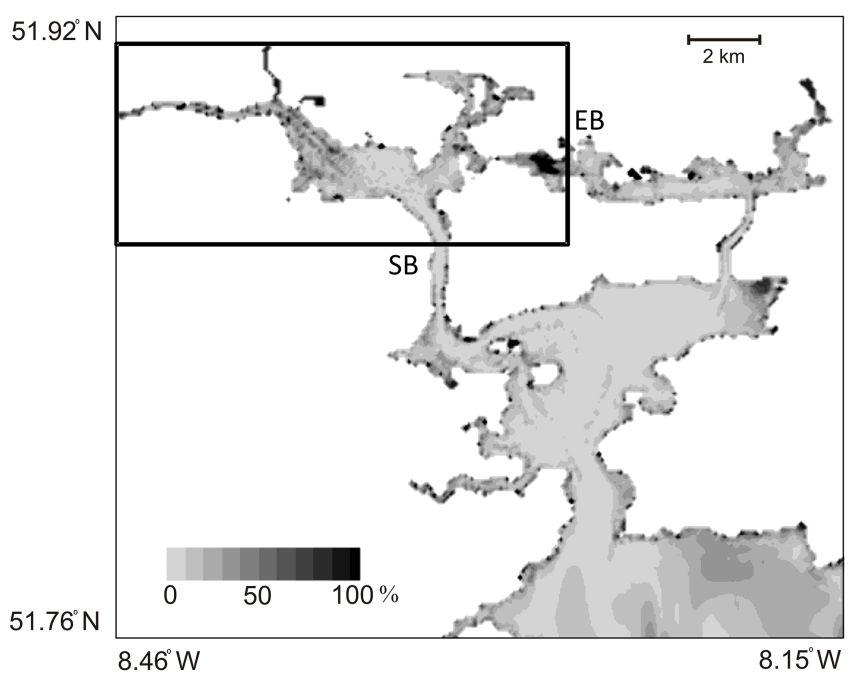

Figure 6. Current velocity $\mathrm{RE}_{\mathrm{T}}(\%)$ in PG90 relative to SG30. Black box shows the extent of CG30 and locations of nested boundaries. EB - east boundary; SB - south boundary.
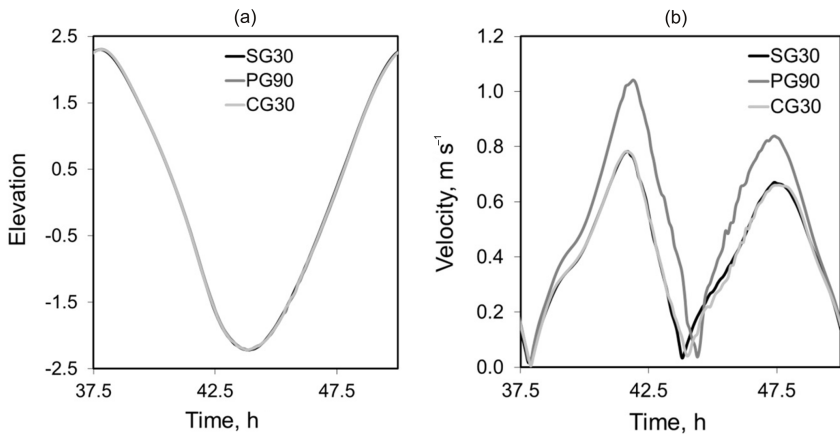

Figure 7. Comparison of (a) water elevations and (b) current velocities at point $\mathrm{C} 1$ in Lough Mahon. Point location shown in Fig. 3.

rent velocities are significantly overpredicted by the PG90 model. Linear regression of current speeds of PG90 against SG30 solution is shown in Fig. 8. As can be seen from this figure, the correlation coefficient between PG90 and SG30 is 0.89 , while slope and intercept are $m=1.24$ and $c=0.03$, respectively.

\subsubsection{CG30 model}

The selection of a child grid domain configuration is sensitive to the location of boundaries that may affect the overall stability and performance of the nested model solution. Suitable CG boundaries must be located in areas of low PG inaccuracy and at a sufficient distance from the area of interest as location of the boundary close to the area of interest may result in boundary errors propagating into the area, causing the accuracy of the solution to deteriorate. On the other hand, boundaries need to be sufficiently close to the area of interest in order to minimize the domain size (computational cost). 


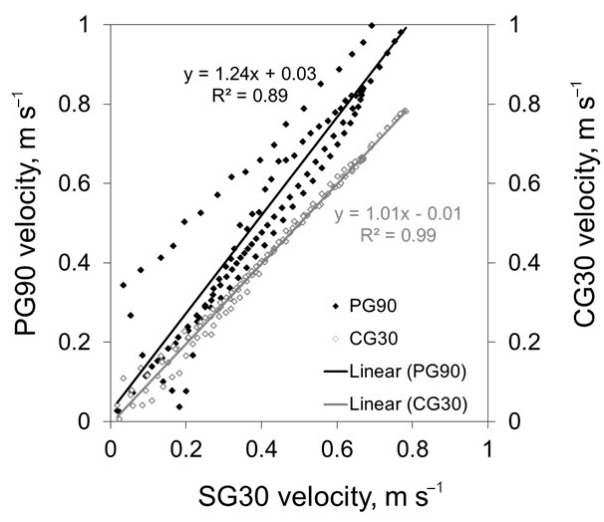

Figure 8. Comparison of modelled velocities for various grid setups at point $\mathrm{C} 1$ in Lough Mahon (point location shown in Fig. 3). Time series data are overlain by a linear trend.

The first level child grid, CG30, was located in the northwest part of Cork Harbour, with the centrally located Lough Mahon (directly feeding to the River Lee estuary) being the area of interest. The boundaries for the CG30 domain were chosen based on the $\mathrm{RE}_{\mathrm{T}}$ distribution plot for the PG90 current velocities presented in Fig. 6. The upper section of Passage West, connecting Lough Mahon with Cork Lower Harbour, was selected as a suitable southern boundary (SB) due to its relatively low $\mathrm{RE}_{\mathrm{T}}$, while the closest suitable location for the eastern boundary (EB) was at a much greater distance from Lough Mahon due to generally high PG inaccuracies in the North Channel.

The accuracy of the CG30 boundary location was assessed by comparing the net fluxes of mass and momentum across the corresponding interfaces in the PG90, SG30 and CG30 models. Net fluxes were calculated normal to boundaries. Mass and momentum fluxes through the SB and EB boundaries are compared in Figs. 9 and 10, respectively. It can be seen that the predominant forcing boundary for the CG30 domain is the SB boundary. The tidally averaged errors in PG90 fluxes relative to the SG30 were approximately $4 \%$ for both mass and momentum, indicating a high level of PG90 accuracy. At the EB boundary, the PG90 accuracy was slightly lower, resulting in error in PG90 mass flux of $5 \%$ and momentum flux of $10 \%$. However, this boundary accounted for a smaller portion of the total boundary forcing, and its distant location from the area of interest allowed boundary errors more time to dissipate. The tidally averaged errors in CG30 fluxes (both mass and momentum) relative to PG90 fluxes were less that $2 \%$ at both boundaries, demonstrating high levels of conservation from parent grid to child grid.

Relative error analysis was also carried out for the entire CG30 model domain with respect to water elevations and velocities, and results of these analyses are summarized in Table 2. The domain-averaged relative error (Eq. 8) in the PG90 water elevations relative to the SG30 were $5.9 \%$, while in the CG30 model this error was reduced to $1.1 \%$. The extent of
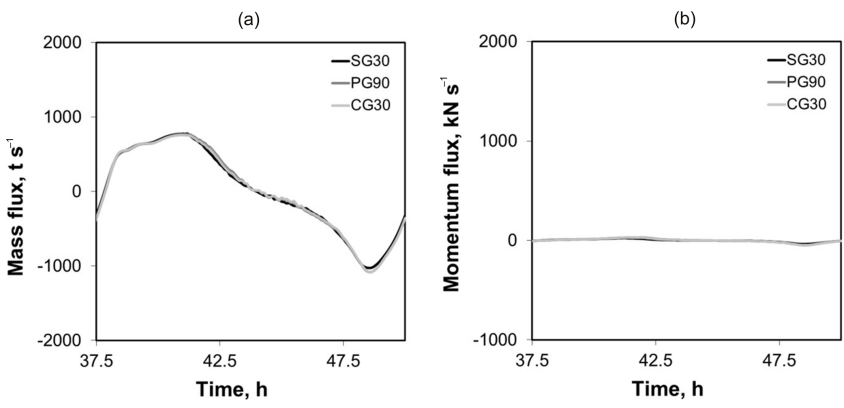

Figure 9. Comparison of (a) mass and (b) momentum fluxes across EB boundary; PG90 and CG30 time series are coincident.

Table 2. Summary of error analyses for PG90 and CG30 models within CG30 model area.

\begin{tabular}{lrr}
\hline & \multicolumn{2}{c}{$\mathrm{SG} 30$} \\
\cline { 2 - 3 } Error analyses parameter & $\mathrm{PG} 90$ & $\mathrm{CG} 30$ \\
\hline Water elevation: & & \\
\hline$-\mathrm{RE}_{D}[\%]$ & 5.9 & 1.1 \\
$-\mathrm{AE}_{D}\left[\times 10^{-2} \mathrm{~m}\right]$ & 8.0 & 1.2 \\
$-\mathrm{RE}_{\mathrm{T}}>1 \%[\%]$ & 94 & 28 \\
\hline Current velocity: & & \\
\hline$-\mathrm{RE}_{D}[\%]$ & 22.4 & 0.5 \\
$-\mathrm{AE}_{D}\left[\times 10^{-3} \mathrm{~m} \mathrm{~s}^{-1}\right]$ & 2.70 & 0.13 \\
$-\mathrm{RE}_{\mathrm{T}}>5 \%[\%]$ & 72 & 4 \\
\hline
\end{tabular}

the domains with $\mathrm{RE}_{\mathrm{T}}$ greater than 1 was $94 \%$ for PG90 and $28 \%$ for CG30. The absolute error (Eq. 9) was also calculated. $\mathrm{AE}_{\mathrm{T}}$ at water level significantly decreased from $8 \mathrm{~cm}$ in PG90 to $1.2 \mathrm{~cm}$ in CG30. In relation to current velocities, $\mathrm{RE}_{D}$ was reduced from a large value of $22.4 \%$ in PG90 to just $0.5 \%$ in $\mathrm{CG} 30$, while $\mathrm{RE}_{\mathrm{T}}$ values exceeding $5 \%$ were found in 72 and $4 \%$ of the PG90 and CG30 domains, respectively.

As shown in Fig. 7, time series of water elevations and current speed show very good agreement between SG30 and CG30 throughout the tidal cycle. This indicates significant improvement in the accuracy of velocity computation using the high-resolution nested CG30 model and is verified by the linear regression analysis shown in Fig. 8. The superiority of CG30 over PG90 when compared to SG30 is clear and confirmed by a correlation coefficient of 0.99 compared to 0.89 . The slope and intercept were also improved for CG30 when compared to PG90; with $m=1.01$ and $c=-0.01$, the CG30 and SG30 model solutions lie approximately on the $45^{\circ}$ line.

These results demonstrate that the application of the nested high-resolution model results in significant improvement in the accuracy of the model solution over the lower-resolution PG solution. Similar to the improvement in model accuracy, 

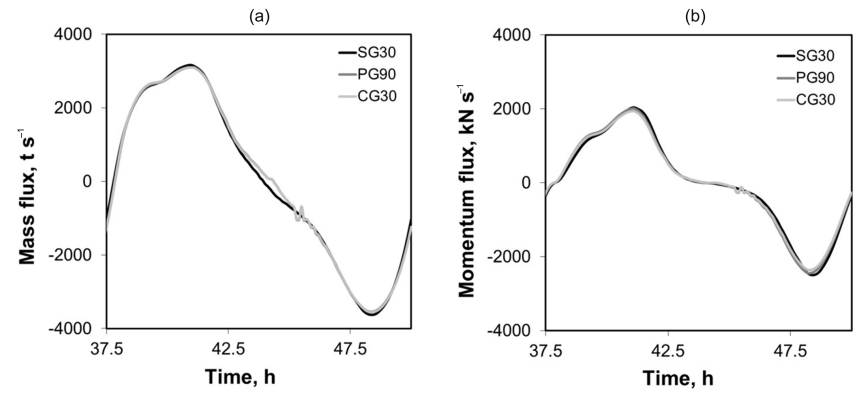

Table 3. Error statistics of water elevations simulated by the CG06 model and measured at Tivoli tidal gauge station. Heights are in metres.

\begin{tabular}{lccccc}
\hline Code & COR & NSD & RMSD & RMSE & RMSdiff \\
\hline CG06_1 & 0.992 & 1.021 & 0.141 & 0.142 & 0.022 \\
CG06_2 & 0.996 & 1.023 & 0.104 & 0.106 & 0.024 \\
CG06_3 & 0.995 & 1.084 & 0.075 & 0.075 & 0.020 \\
\hline
\end{tabular}

Figure 10. Comparison of (a) mass and (b) momentum fluxes across SB boundary; PG90 and CG30 time series are coincident.

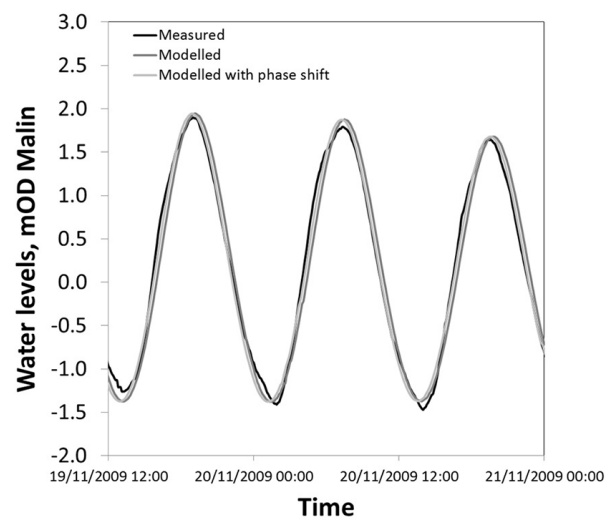

Figure 11. Water elevations modelled by CG06 and measured at Tivoli tidal gauge station.

an equally significant reduction in computational effort was achieved. For example, the application of the MSN_Flood model to level 1 domain nesting yields 21 min simulation time for the PG90-CG30 model; this is contrasted by $80 \mathrm{~min}$ simulation time for the SG30 model. Thus the nested model runs 3.8 times quicker than the single-grid model.

\subsubsection{CG06 model}

In contrast to the CG30 grid being fully embedded within the PG90 grid, in the second level of nesting CG06 is only partially nested within its parent CG30 (Fig. 4). Approximately $38 \%$ of wet cells in CG06 overlap CG30. This is a hybrid boundary structure where the east boundary is prescribed using hydrodynamic data from the parent model, while the west boundary is prescribed using measured data. The west boundary is a flow boundary, with River Lee inflows extracted from river gauging station 19011. The east boundary is a water elevation boundary where water elevations are supplied along the boundary by the CG30 model. The location of the latter boundary was selected to correspond to the position of the Tivoli tidal gauge station and therefore to contribute to model validation (see Fig. 3 for location of Tivoli gauge).

Validation of the CG06 model is conducted for the flood event of November 2009, which due to a combination of

heavy river discharges and high tides coinciding with moderate surges resulted in extensive inundation of the area delineated by this nested grid. Figure 11 compares time series of water elevation computed at the CG30-CG06 nested boundary (east boundary) against tidal gauge records from the same location. Overall, there is a very good agreement between predicted water elevations and measured data. The high degree of model accuracy is manifested by high correlation (0.992) and a low value of RMSdiff $(0.022 \mathrm{~m})$ shown in Table 3 (model CG06_1). Both the RMSE $(0.142 \mathrm{~m})$ and centred RMSD $(0.141 \mathrm{~m})$ indicate that the model is able to reproduce variability of water elevation with a good accuracy (order $0.14 \mathrm{~m}$ ). Further, a small difference between these two statistical measures implies that the mean values of observations and simulation are very close. Interestingly, the accuracy of the CG06 model is improved when a 6 min phase shift (one record time step) between observations and simulation is artificially introduced (model CG06_2 in Table 3). This results in RMSE (RMSD) reduction to $0.106 \mathrm{~m}(0.104 \mathrm{~m})$ and an increase of correlation to 0.996 . It is deemed then that there is a phase lag between model and observations of approximately one observational time step. Another aspect of the analysis involved temporal occurrence of an error. As the model-observation discrepancies are observed around low water levels (which is not so significant to this study), by not considering negative water elevations (below $0 \mathrm{~m}$ OD Malin) the RMSE is further reduced to $0.075 \mathrm{~m}$ (model CG06_3 in Table 3). Such a level of agreement between model and observation is considered to be satisfactory.

The effect of horizontal resolution on model skill is also examined. This is carried out by comparing the model performance at 6 and $2 \mathrm{~m}$ resolutions. For this purpose a single-grid $2 \mathrm{~m}$ reference model (SG02) covering the area delineated by the CG06 model was developed. Figure 12 presents the distribution of water level $\mathrm{RE}_{\mathrm{T}}$ in the CG06 solution relative to the SG02 reference solution. In general, errors in CG06 outside the Cork city centre are very low $(<10 \%)$, implying that flooding in the rural area of Cork is well resolved using the $6 \mathrm{~m}$ grid. In contrast, significantly higher errors are obtained in Cork city (CG02 domain) and in particularly in areas of narrow, dense streets, where errors exceed $30 \%$. Here, an increase in model resolution leads to a significant reduction in errors. This implies that the next level of nesting is required to improve the model accuracy in the city centre. 


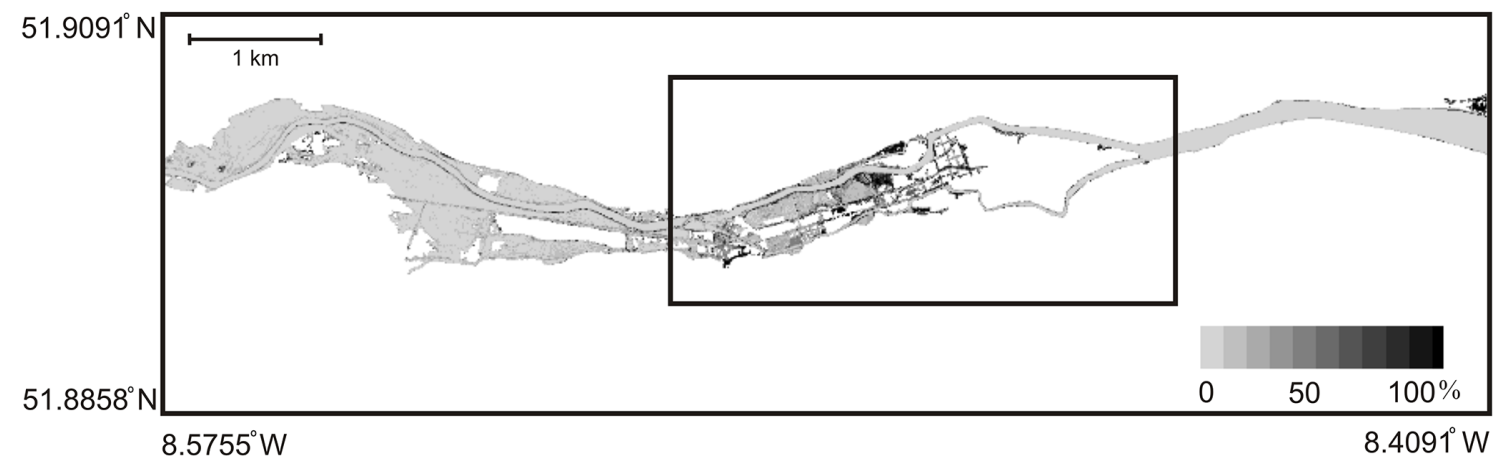

Figure 12. Water level $\mathrm{RE}_{\mathrm{T}}(\%)$ in CG06 relative to SG02. Black box shows extent of CG02 and locations of nested boundaries.

Table 4. Error statistics of water elevations at four locations simulated by the CG06 and CG02 models. Heights are in metres.

\begin{tabular}{lccccr}
\hline Code & COR & NSD & RMSD & RMSE & RMSdiff \\
\hline CG02_1 & 0.995 & 1.033 & 0.080 & 0.111 & -0.081 \\
CG02_2 & 0.997 & 1.014 & 0.109 & 0.195 & -0.181 \\
CG02_3 & 0.998 & 1.045 & 0.056 & 0.076 & -0.064 \\
CG02_4 & 0.999 & 0.999 & 0.006 & 0.006 & 0.000 \\
\hline
\end{tabular}

\subsubsection{CG02 model}

Finally, the highest-resolution $2 \mathrm{~m}$ model (CG02), fully embedded within CG06, covers the urban area of Cork city; this area is particularly prone to flooding. In the first step of model skill analysis, water elevations simulated by the CG06 and CG02 models at four locations along the river channel are compared in Fig. 13 and statistically summarized in Table 4. Again, the November 2009 flood event was used as a benchmark. Close to the east boundary, at point CG02_4 (see Fig. 14 for point location), both models perform almost identically, and this is visually and statistically confirmed in Fig. 13d and in Table 4, respectively. Discrepancies between the CG06 and CG02 models increase with distance from the nested east boundary and are manifested by overall higher water elevations computed by the coarser CG06 model. Location CG02_2 (Fig. 13b) shows the biggest discrepancy evidenced by the statistical measures $\mathrm{RMSE}=0.195 \mathrm{~m}, \mathrm{RMSD}=0.109 \mathrm{~m}$ and RMSdiff $=-0.181 \mathrm{~m}$. Despite overprediction of water elevations by the CG06 model, the general water level trends in the two models are in good agreement $(C O R=0.997)$. Another important advantage of a high-resolution model is an improved numerical stability of the model solution. As can be seen from Fig. 13a-c, some infrequent random oscillations in water levels occurring in CG06 from numerical instability due to insufficient grid resolution are not present in the finer CG02 model.

The numerical instability of the MSN_Flood model is directly related to the grid resolution and results from an ADI
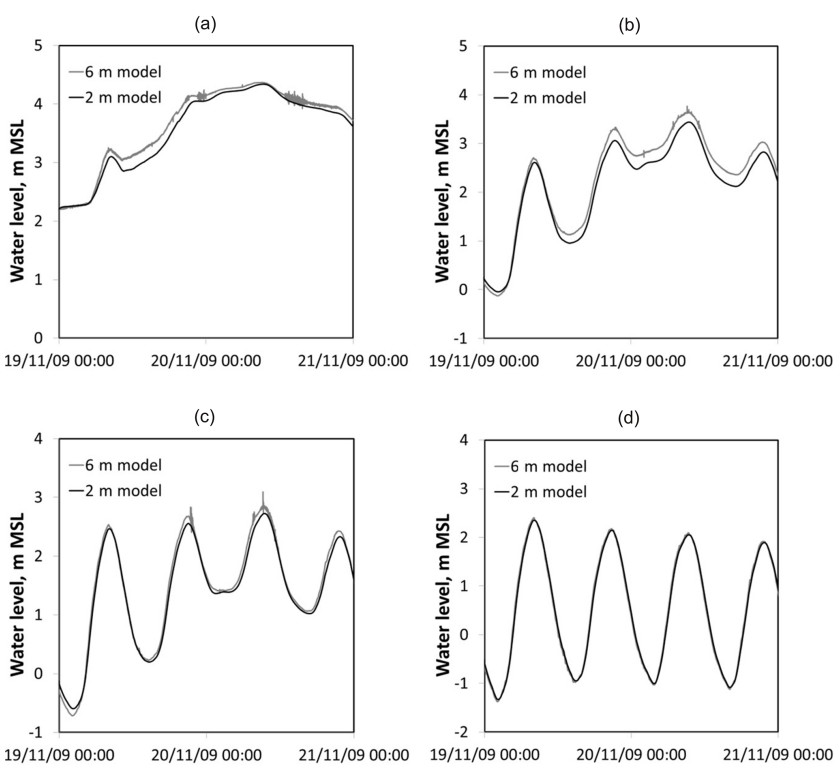

Figure 13. Time series of water elevations predicted by CG06 and CG02 at four locations: (a) CG02_1, (b) CG02_2, (c) CG02_3 and (d) CG02_4. Point locations shown in Fig. 14.

algorithm used in the model's solution procedure. In general, the models using ADI are very accurate numerically in modelling flows; however, in the presence of a discontinuity, such as in regions of sharp gradients (e.g. velocity gradients, elevation gradient or high elevations), the numerical models using such schemes are prone to generate spurious numerical oscillations (Kvočka et al., 2015). A common solution used to reduce these oscillations is to increase the grid resolution so the slopes over numerical grids are milder. Comparing time series outputs from CG06 and CG02 (Fig. 13), it is evident that increasing resolution of the model significantly reduces numerical errors and hence oscillations.

The effect of improved horizontal resolution is analysed spatially by means of $\mathrm{RE}_{\mathrm{T}}$ distribution plots. As shown in Fig. 12, the $2 \mathrm{~m}$ resolution is essential to resolve small-scale processes of complex urban area. Figure 14 compares $\mathrm{RE}_{\mathrm{T}}$ 


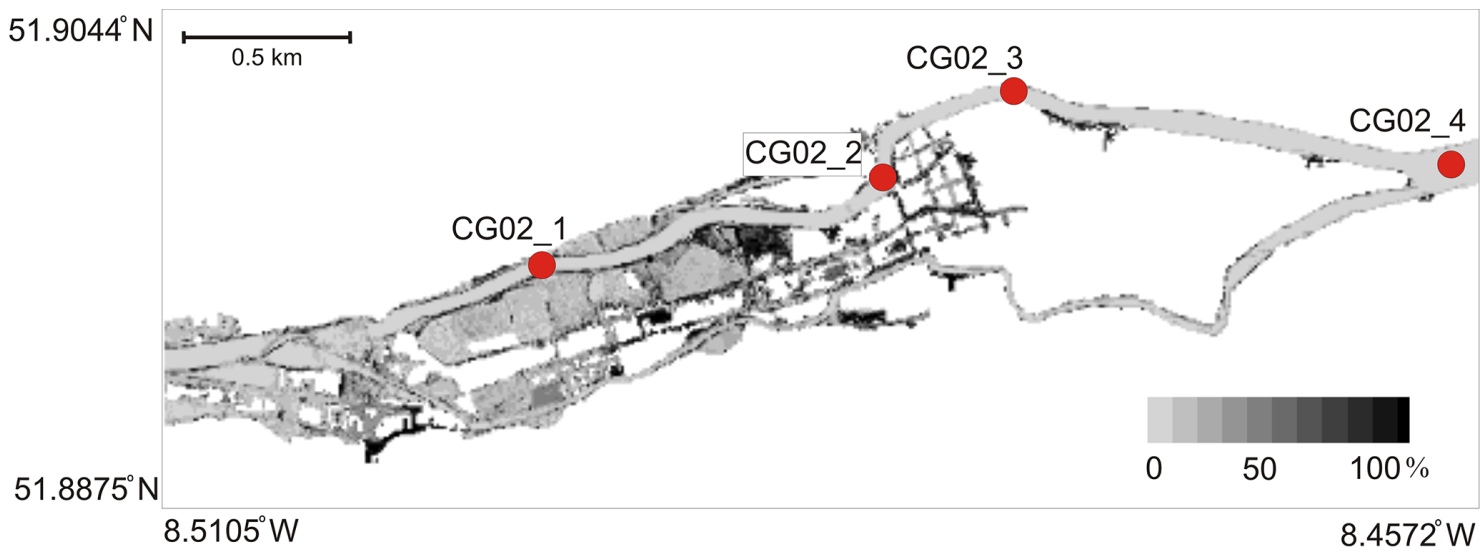

Figure 14. Water level $\mathrm{RE}_{\mathrm{T}}$ (\%) in CG02 relative to SG02. Red dots denote points used in water level analysis (see Fig. 13).

between $\mathrm{CG} 02$ and $\mathrm{SG} 02$. In general, $\mathrm{RE}_{\mathrm{T}}$ is quite low at $10 \%$ in the western part of the city along river banks, increasing in eastward direction to $20 \%$ in narrow streets of city centre. This is a considerable improvement when compared to $\mathrm{RE}_{\mathrm{T}}$ in $\mathrm{CG} 06$ relative to $\mathrm{SG02}$. Moreover, as CG02 achieves a similar level of accuracy to SG02, the computational cost is significantly reduced and constitutes an enormous $96 \%$ savings.

From this analysis it can be seen that the CG06-CG02 nesting results in a model performance generally comparable to the single-grid SG02 model but at a significantly reduced computational cost when compared to the single-grid model.

The ultimate conclusion from the model validation is that MSN_Flood facilitates significant improvements in model accuracy without incurring the computational expense of high spatial resolution over the entire model domain. The model setup constitutes a rigorous test of model performance and on that basis it can be further concluded that the model is applicable to situations where nested boundaries are located in complex urban floodplains that periodically wet and dry.

\subsection{Urban flood modelling}

For most of the time, city streets are dry, and rivers draining the hinterland are contained within well-defined river banks or walls. However, when extreme flood events occur, rivers may burst their banks and the city streets become water conveyance channels. The simulation of the hydrodynamics associated with rapid urban flood events is complex; many significant issues must be addressed such as flooding and drying, spatial resolution, domain definition, frictional resistance and boundary descriptions. When modelling flood events, the mathematical formulation of the nested boundaries that permit flooding and drying is of particular importance. Also, the horizontal resolution necessary to resolve small-scale processes must be considered. In particular, these aspects of the MSN_Flood model will be discussed in this section.

\subsubsection{Extreme flood event}

On 19 and 20 November 2009 high River Lee flows combined with high astronomical tides and moderate surge caused localized overtopping/breaching of the river banks, resulting in widespread flooding of Cork city. Evolution of the flood wave propagation simulated by the CG02 model is shown in Fig. 15. Maximum flooding was reached at 09:30 LT on 20 November 2009 around the time of high tide and approximately $5 \mathrm{~h}$ after peak discharge of River Lee. At this juncture over 62 ha of Cork city had been flooded. The most affected zone was the city centre located between the north and south channels of the river; this area is a lowlying island that over centuries was gradually reclaimed from marshland and its low-lying topography combined with the influence of river, estuary and harbour makes the area particularly vulnerable to flooding.

The accuracy of the urban inundation simulation was assessed against field observations of inundation extent and maximum heights of flood waters. The observed and modelled ultimate extents of flooding in the city are shown in Fig. 16; the hindcasted extent of inundation matches very well that observed during the flood event. With regards to flood level heights, observed water level marks were collected and post-processed by OPW at 38 survey points across the flooded area; their distribution is shown in Fig. 17. The survey point data were subsequently used to calibrate the model. Initial calibration tests showed that the model was most sensitive to bottom roughness coefficient. An extensive statistical analysis of bed roughness parameterization was used to provide an accurate model solution for flood inundation; details of that analysis are presented in Olbert et al. (2017). The best-fitting results $(R=0.97$; $\mathrm{RMSD}=0.26)$ were obtained for the following roughness values: upper channel $=0.90$; lower channel $=0.90$; roads $=0.1$; city floodplain $=0.1$; and upstream floodplain $=0.30$. Figure 18 provides visual assessment of the best-fit model skill; good agreement between the model and observations is achieved 


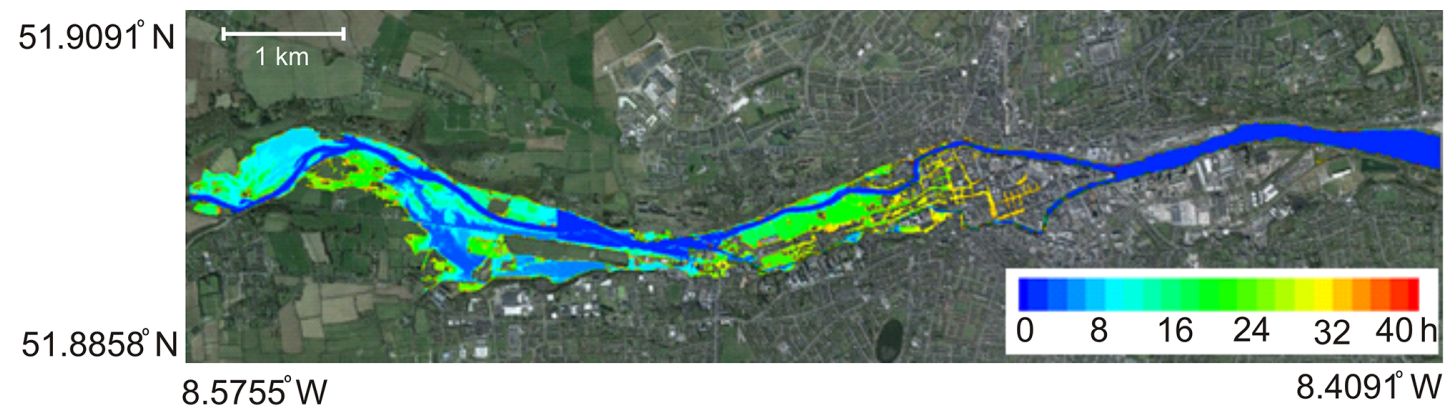

Figure 15. Temporal evolution of flood wave through upper and lower floodplains of Cork city during the November 2009 flood event modelled by CG06; contours represent $2 \mathrm{~h}$ intervals.

(a)

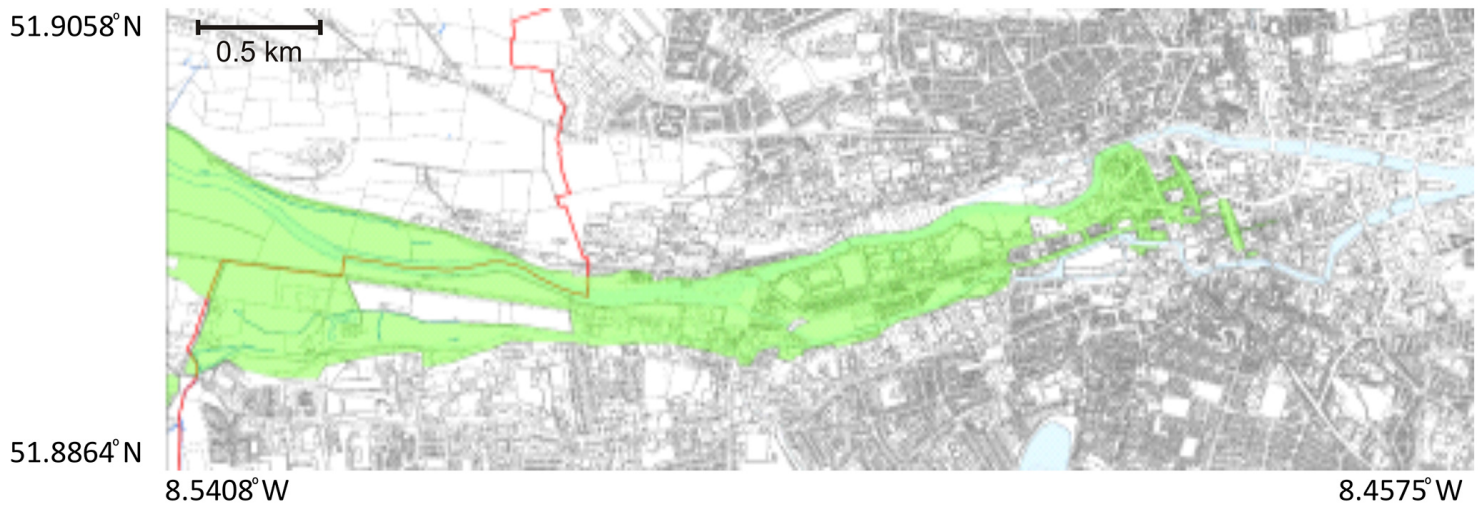

(b)

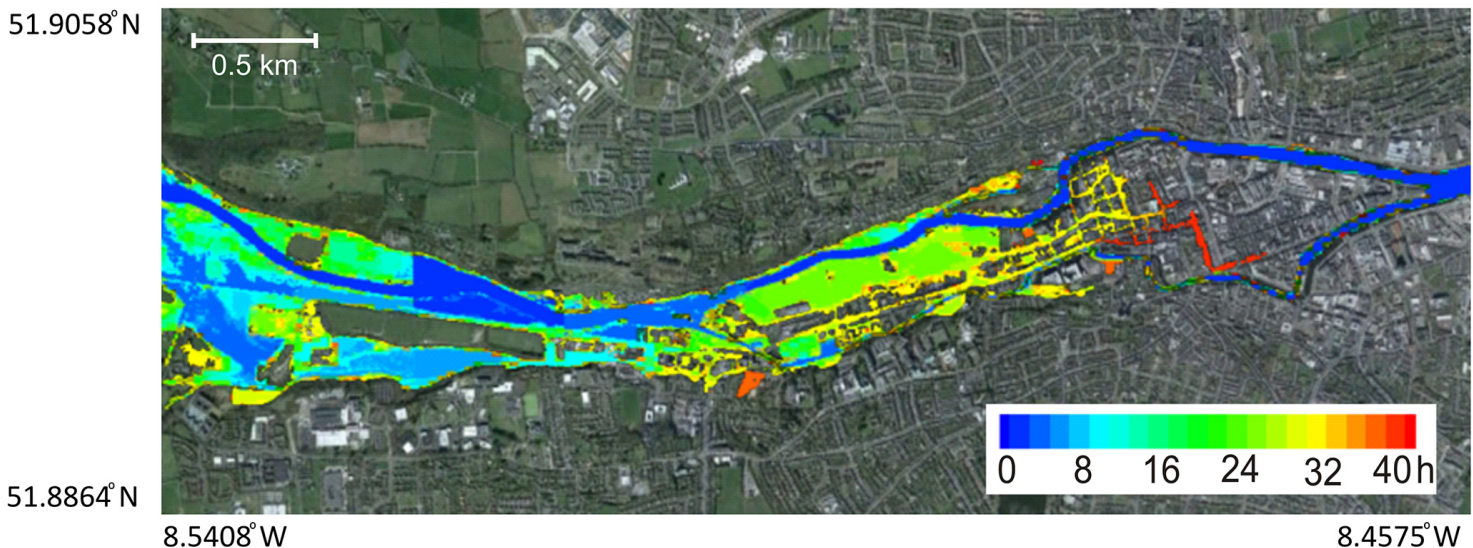

Figure 16. Maps of flood inundation (a) observed by OPW and (b) modelled; contours represent $2 \mathrm{~h}$ intervals. Evolution of modelled flood wave is a combined output of CG06 and CG02.

as the model solution falls on the $45^{\circ}$ line. Interestingly, better agreement was found for survey locations in floodplains than at points adjacent to the river bank. This could be attributed to the fact that the majority of survey points are located away from the channel edge (many are actually at the floodplain edge).

\subsection{Moving boundary}

The specification of a nested boundary in a flood-prone area is particularly problematic; nested models developed so far prohibit flooding and drying along open boundaries. This problem has been overcome in MSN_ Flood; its unique 


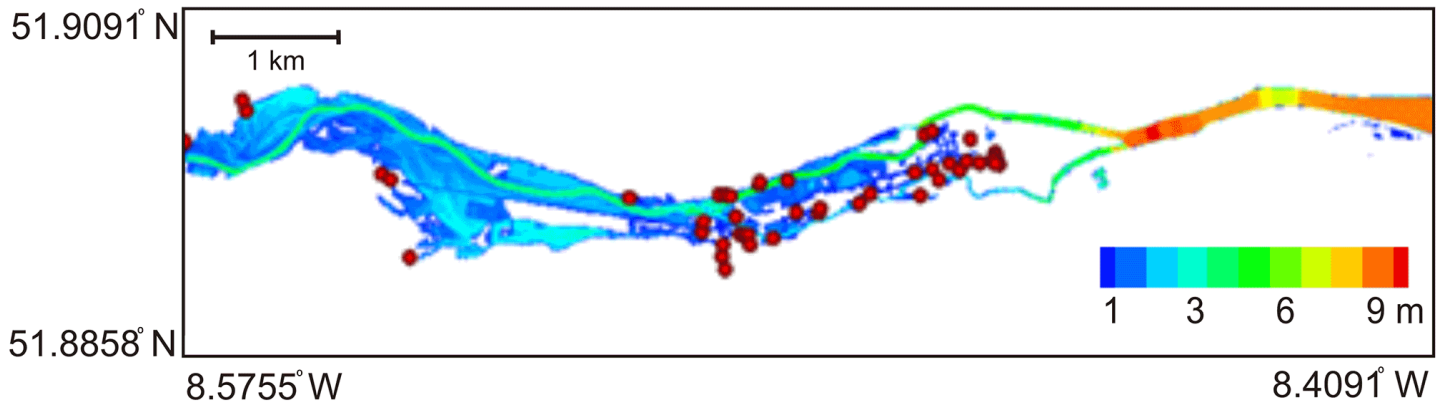

Figure 17. Maximum water levels during November 2009 flood event and water level survey points marked as red dots.

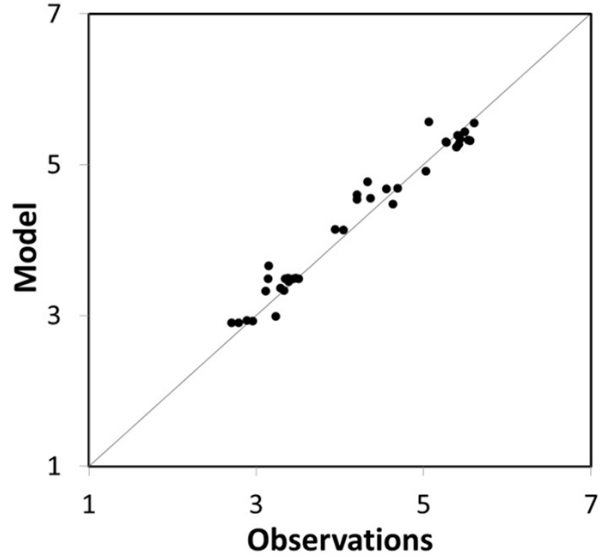

Figure 18. Comparison of modelled and observed maximum water elevations at 38 survey stations.

mathematical formulation of the nested boundary involving ghost cells, internal boundary formulation and adaptive interpolation ensures stable flooding and drying of boundary cells. In MSN_ Flood, any nested boundary can be placed within a flooding and drying zone and therefore may be subject to significant lateral expansion and contraction. Moreover, the internalization of the boundary allows the flooding and drying mechanism to approach the boundary of the nested domain from either upstream or downstream. As the boundary alternatively floods or dries, the number of active boundary cells expands and contracts accordingly. Depending on local topography, not only the length of the boundary may change, but also the number of active boundaries changes. Such a boundary is therefore a complex, noncontinuous, moving boundary that spatially and temporally changes its characteristics. This is a significant aspect of this research.

In the model setup, the urban CG02 model is entirely embedded within the CG06 model; mass and momentum from the $6 \mathrm{~m}$ model are transferred to the $2 \mathrm{~m}$ model via two nested boundaries - the western boundary, transferring River Lee waters from the upper to the lower channel of the river (it also geographically divides the floodplains into upper and lower floodplains), and the eastern boundary, exchanging waters with the estuary. The western boundary of CG02 is located on the upstream fluvial floodplain, which is prone to wetting and drying. A cross section through this boundary illustrating the steep gradients of the river channel bathymetry and the topography of the adjacent urban floodplains (which includes buildings) is shown in Fig. 19. The temporal progression of water levels throughout the November 2009 flooding is also plotted. The reference water level at simulation time $t=4 \mathrm{~h}$ corresponds to a $187 \mathrm{~m}^{3} \mathrm{~s}^{-1}$ river flow (19 November 2009 at $01: 30$ ). At this juncture the flow greatly exceeds the average river flow of $40 \mathrm{~m}^{3} \mathrm{~s}^{-1}$ as it results from increased discharges from Inniscarra Dam. The storage capacity of Inniscarra Reservoir had been reached after a month-long period of record-high rainfalls and heavy downpours on 18 and 19 November. Over the course of the subsequent $28 \mathrm{~h}$ the discharges further increased to reach a maximum value of $560 \mathrm{~m}^{3} \mathrm{~s}^{-1}$ at $02: 30$ on 20 November. The water level at the boundary increased from $4.57 \mathrm{~m}$ OD at 22:30 on 18 November to a peak of $5.74 \mathrm{~m}$ OD $28 \mathrm{~h}$ later.

The extensive inundation of the upper channel floodplains (upstream floodplains) has a major effect on the western boundary of the CG02 model. It can be seen in Fig. 19 that as the flooding progresses to a simulation time of $8 \mathrm{~h}$ a second wetted boundary is created south of the main channel boundary due to bifurcation of flood waters into two channels (called here the main and side channels) approximately $1.2 \mathrm{~km}$ upstream of the boundary. Importantly, there is a significant difference in water elevation of $0.41 \mathrm{~m}$ between the two channels of the boundary. This results from the topography of the upstream floodplains and therefore local flow conditions. The reason for the difference in water elevations along the two sections of the boundary can be explained with the help of Fig. 20, showing three cross sections, including one (cross section 3) located close to the nested western boundary. As simulated by the CG06 model, downstream from cross section 1, representing the maximum cross-sectional extent of the inundated area, flood waters must flow around an elevated strip of rural land and so split at this point into two floodplain channels. This is shown in cross section 2, located at mid-length of this $1 \mathrm{~km}$ long strip of 


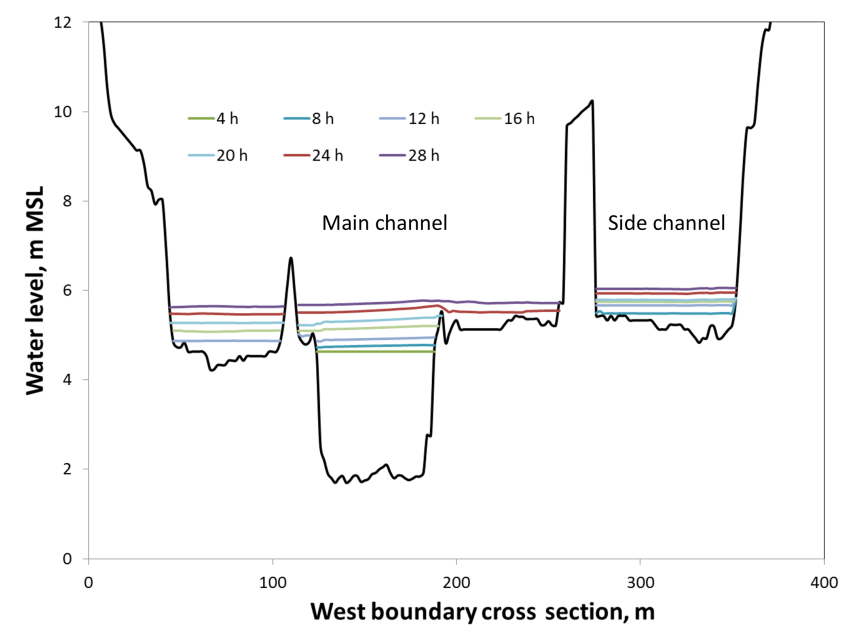

Figure 19. Cross section through west boundary of CG02 with water elevation marks for selected time points.

land; here the water elevation difference between two channels is $0.31 \mathrm{~m}$. This elevation difference further increases to $0.41 \mathrm{~m}$ near the nested boundary (cross section 3 ).

The temporal rise of water levels at a number of points across the western nested boundary is shown in Fig. 21. Series $\mathrm{A}$ represents the main river channel, series $\mathrm{B}$ and $\mathrm{C}$ correspond to points adjacent to the river channel, and series $\mathrm{D}$ is located in the side channel. The difference in water elevations between the two boundaries is apparent throughout the entire flooding period, though it is reduced with the progress of flooding.

An interesting characteristics of the moving boundary is the change in its length. As flood waters continue overtopping the river banks, the area of inundation increases and is reflected in the elongation of the boundary. The length of the main channel boundary is initially equal to the river width; this nearly doubles during flooding as shown for $t=12 \mathrm{~h}$ in Fig. 19. The temporal evolution of flooding through the boundary clearly demonstrates that the nested boundary is a discontinuous moving boundary with a variable head.

The numerical stability of such dynamically changing properties of nested boundary is an important aspect of nesting procedures. Overall, a change in length as well as division into separate subsections does not markedly impact computational stability nor model performance. In fact, as shown in Fig. 14, $\mathrm{RE}_{\mathrm{T}}$ computed over the flooding period remain low within the $\mathrm{CG} 02$ domain despite significant changes to nested boundary configurations and flow conditions.

As demonstrated in this section, MSN_Flood has been developed in a general-purpose manner that through stable and accurate moving boundary provides a high degree of choice and flexibility regarding the location of the boundaries to the nested domain.

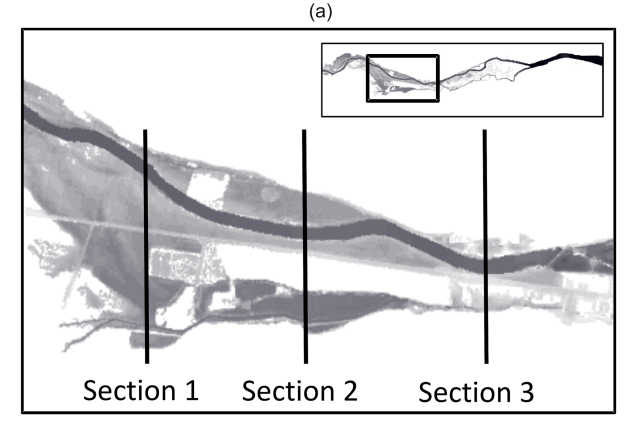

(b)
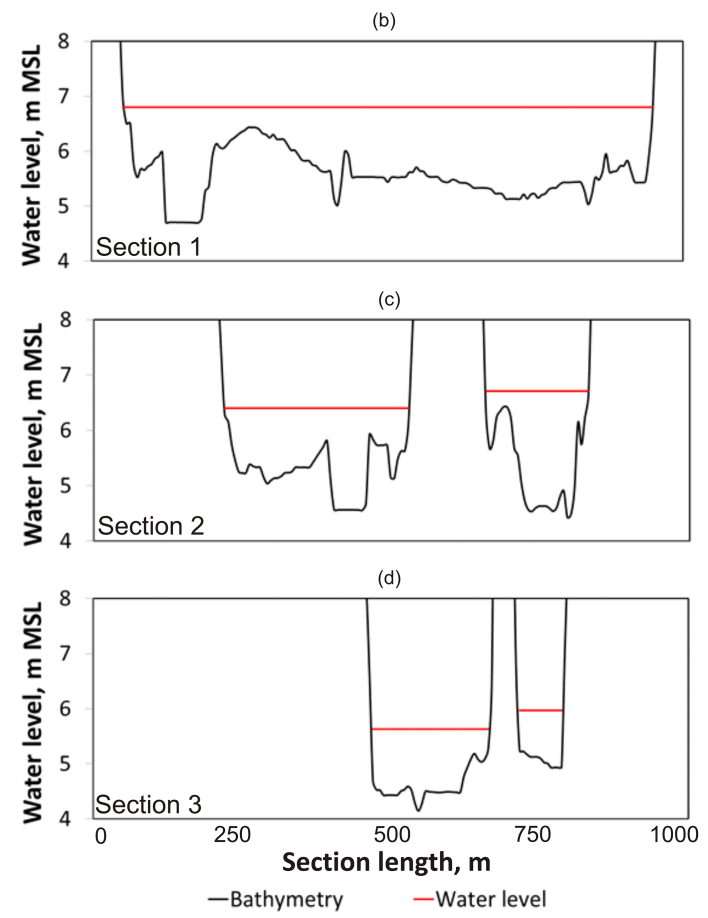

Figure 20. (a) Flood extent in upper floodplains and (a-c) water elevations at three cross-sections during flood simulated by CG06.

\subsection{Model resolution}

Due to the highly irregular topography of urban environments and the highly dynamic flows involved, urban flooding is a complex problem. Most of the flood models developed so far have focused on rural or semi-developed floodplains where isolated large structures can be modelled while small objects are ignored or parameterized as bottom friction (Brown et al., 2007). Such modelling does not implicitly account for locking effects of building on flow. As the presence of buildings may substantially increase flood extent when compared with undeveloped floodplains, the role of high-resolution discretization is paramount. However, as Brown et al. (2007) found, the greatest source of modelling error with respect to grid resolution is associated with the steepest gradients in topography, which are susceptible to interpolation error. 


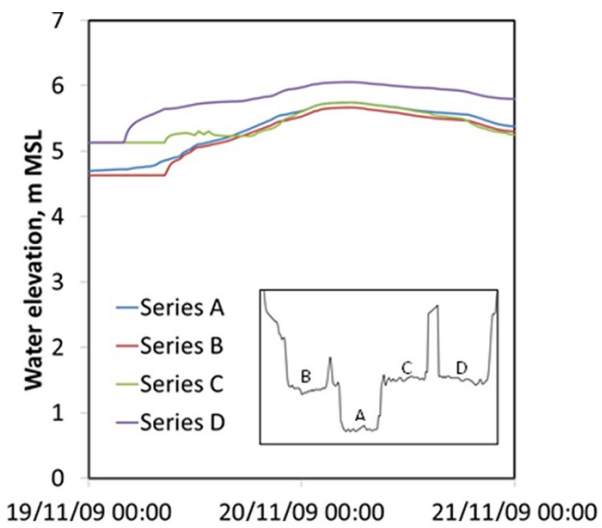

Figure 21. Time series of water elevations across the western nested boundary of CG02.

(a)

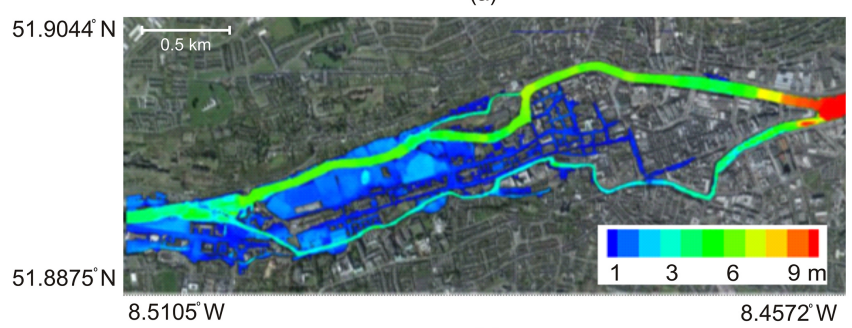

(b)

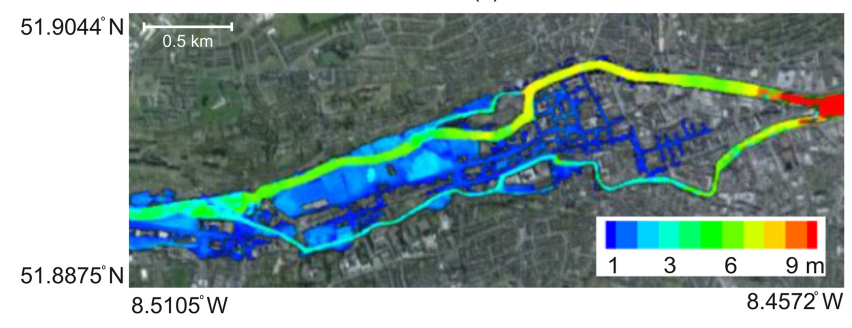

Figure 22. Comparison of flood extent simulated by (a) CG02 and (b) CG06. Contours represent water levels (m).

Modelling of flood flow through an urban area is difficult because of its need for stable and accurate solution of the flow equation (Brown et al., 2007). Since accurate modelling requires a resolution commensurate with flow features, dense street network flows through urban floodplains can only be fully resolved with a sufficiently high resolution. However, satisfactory model resolution, and thus accuracy, incurs computational expense; a balance between these two contradicting factors provides an optimal solution. Gallegos et al. (2009) found that a $5 \mathrm{~m}$ resolution mesh that spans a street by approximately three cells achieves such balance. The characteristics of urban residential areas of southern Californian investigated in their study is different than that of an old European towns comprising narrow, dense streets as Cork city. It follows that the $5 \mathrm{~m}$ model resolution is insufficient to resolve flow dynamics in such city centre street networks. (a)

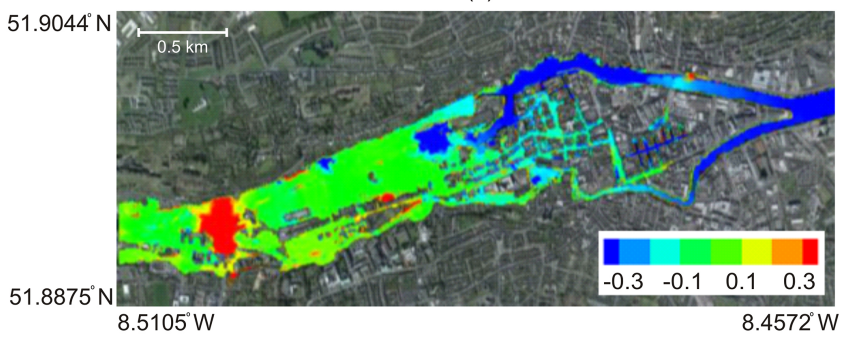

(b)

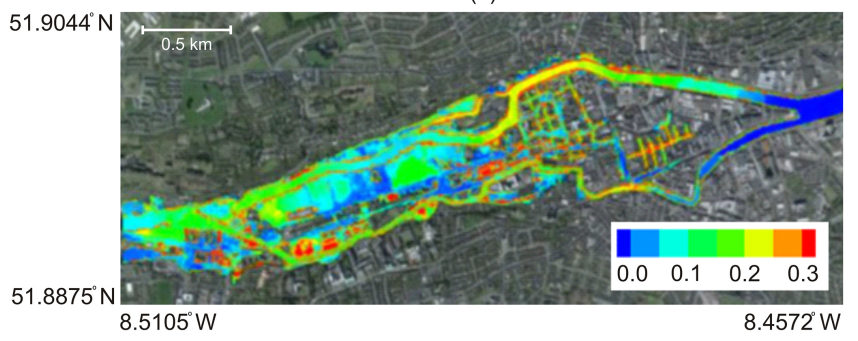

Figure 23. Contour plots of (a) difference in water elevations (m) between CG06 and CG02, and (b) RMSE over time.

In order to analyse the overall effect of model resolution on simulation results, CG06 and CG02 model results are compared. Visual comparison of flood inundation can be made from Fig. 22, which shows CG06 and CG02 model outputs representing the maximum extent of inundation during the November 2009 flooding. There is a discrepancy in the extent and magnitude of flooding between the two models. Some zones and streets do not get flooded in the CG06 model, which may be caused by the coarse representation of the street network and associated lack of connectivity between certain streets, while in other zones flood water is present in areas which remain dry according to observations and CG02 output. Figure 23a shows the difference in water elevations between CG02 and CG06 interpolated onto the $2 \mathrm{~m}$ grid. It is clear that both the height and area of flooding are affected. The absolute difference in water level is on average $0.13 \mathrm{~m}$ and is underestimated by the $6 \mathrm{~m}$ model by up to $0.4 \mathrm{~m}$ in the upper section of river and overestimated by approximately $0.3 \mathrm{~m}$ in the lower section. Figure 23b shows a spatial distribution of RMSE between two models. There is a noticeable reduction in model performance at coarser resolution of $0.08 \mathrm{~m}$ RMSE over the entire domain, and the error is generally larger in the dense street network of the urbanized zone. Based on model results, it is clear that a substantial portion of the error results from the coarse representation of topography since its gradient is greater that the slope in water surface; however, some small portion of the error could be attributed to errors in lidar data ( $\sim 0.1 \mathrm{~m}$ RMSE according to Bates et al., 2010) as well as interpolation from a 6 down to $2 \mathrm{~m}$ grid.

Another comparative measure involves a computation of relative differences (Eq. 10) in inundated area and flood water volume between fine- and coarse-grid models at a partic- 


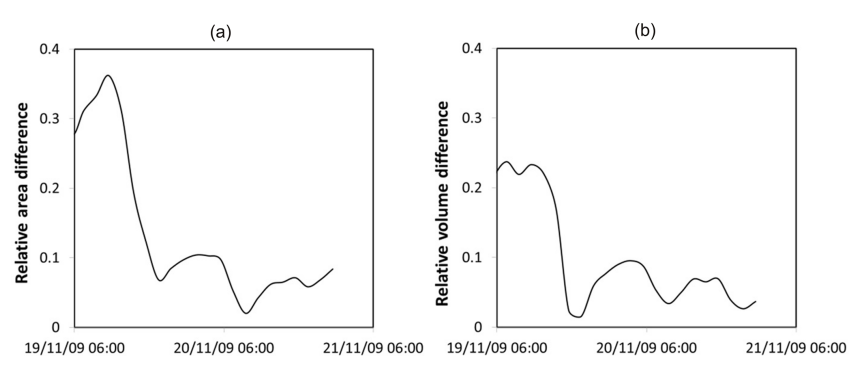

Figure 24. Evolution of the relative difference in (a) total area of inundation and (b) volume of water in inundated area between CG06 and CG02. See text for explanation of relative difference.

ular time. Figure 24a and b show the evolution of differences between CG02 and CG06 solutions in inundated areas and volumes throughout the simulation. The significantly high relative difference in the area at the initial stage of flooding reaching $36 \%$ is misleading as the relatively small total inundated area with a small flood time lag results in large discrepancies at this stage (ca. 11 ha). Nevertheless, when the flooding is more pronounced (over 30 ha, max 62.6 ha) the relative difference is still up to $10 \%$. With regards to flood water volume in inundated areas the difference is over $20 \%$ during the first hours of flooding and still remains as high as $10 \%$ throughout the flood peak, only falling to below $10 \%$ when the flood recedes. The total RMSE of inundated area and volume between 2 and $6 \mathrm{~m}$ models is 3.4 ha and $21367 \mathrm{~m}^{3}$, respectively. This comparison demonstrates that horizontal resolution is of paramount importance when simulating flows through complex topography. It seems that for Cork city centre, comprising a dense network of narrow streets, neither the $5 \mathrm{~m}$ resolution requirement nor the threecell street span would resolve complex flood flow at a satisfactory level of accuracy.

\subsection{Flood water velocities}

Another significant advantage of MSN_Flood is its ability to simulate the velocities of flood waters. As opposed to simplified 2-D hydraulic models frequently used in urban flooding, the hydrodynamic MSN_Flood includes both the continuity and momentum equations, solving for both water elevations and water velocities. Figure 25 shows an example of flood water velocities computed by MSN_ Flood in a selected area of Cork city centre blown up for ease of viewing; one can see flood waters in both the river channel and the urban floodplain. This zone is characterized by fast-flowing shallow water subject to rapid transitions as it flows down through the steep section of recreational grounds adjacent to the river channel. The city downtown, in contrast, is a ponding area with relatively stagnant waters.

Knowledge of velocity fields facilitates better understanding of flood water hydrodynamics and in particular the mechanisms of flood propagation. The routes and speeds of flood

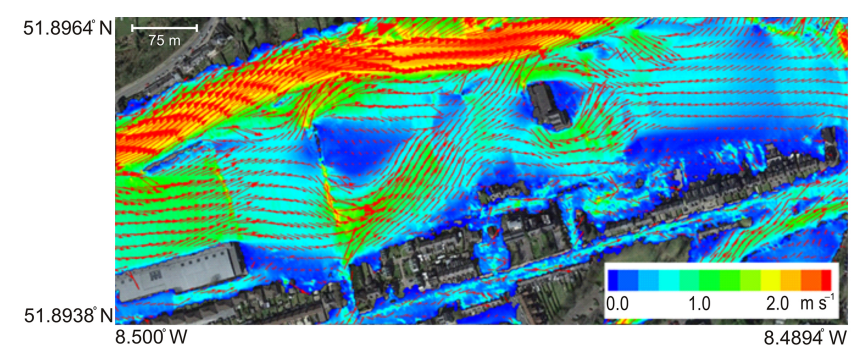

Figure 25. Map of velocity contours $\left(\mathrm{m} \mathrm{s}^{-1}\right)$ with vectors showing magnitude and direction of velocities in the downstream floodplains of Cork city.

waves provide important information for the evaluation of flood risks to people's safety and to property, as well as to the planning and actions of emergency response teams.

\section{Discussion}

Inundation of coastal areas due to coastal and/or fluvial urban flooding mechanisms is a very complex hydrological phenomena, and developing a modelling system to accurately simulate it is not a trivial task. The research presented in this paper demonstrates that the concept of nesting models is very suitable for complex urban coastal flooding as they facilitate the development of an integrated system capable of resolving hydrodynamics at spatial scales commensurate with flows and physical features of the region of interest. The modelling system adopted here determines physical processes simultaneously at different scales ranging from bay-size circulation $(90 \mathrm{~m})$ through mesoscale processes of coastal waters at $30 \mathrm{~m}$ resolution down to the ultra-high-scale environment of $2 \mathrm{~m}$. Validation results show that the model performs well at each of these scales.

The MSN_Flood model developed for use in this research is well suited for high-resolution urban flood simulation for a number of reasons. Firstly, it allows smooth transition of the model solution between coastal waters and river floodplains while giving a very high level of conservation of mass and momentum between parent and child grid (Nash and Hartnett, 2010). Through incorporation of ghost cells and formulation of a dynamic internal boundary, MSN_Flood is designed to minimize boundary formulation error and therefore to transfer mass and momentum across the nested boundary without loss of nested solution accuracy. The reduction in boundary errors yields also a significant improvement in model stability at the nested boundary and CG accuracy. This in turn permits stable flooding and drying at the boundary; moreover, these process are allowed to approach the boundary of the nested domain from either upstream or downstream. The so-called moving boundary allows then embedding of a child grid model within the parent model in areas where the nested boundary may wet or dry, making the model highly flexible in application. Interestingly, such highly re- 
duced boundary formulation errors are achieved in a nesting mechanism where the nested boundary comprises only two cells of columns or rows (ghost cells and internal boundary cells). For comparison, in many nested models poor accuracy due to boundary formulation errors is commonly compensated by indirect solutions such as boundary configuration (e.g. location). For example, Kashefipour et al. (2002) in order to reduce possible nesting error dynamically link a 2-D coastal model with a 1-D river model by using overlapping grids at the boundary - a common area where boundary values are exchanged between two models. Such a model setup is not required in MSN_Flood, where accurate exchange of boundary conditions occurs along a boundary.

Secondly, the model has virtually no limit to the number of specified nesting levels (and spatial resolution) and is primarily constrained by computational effort rather than numerical stability. The highest resolution of $2 \mathrm{~m}$ set for this study was dictated solely by the resolution of available lidar data, and higher resolutions are easily achievable if suitable terrain data are available. For example, a $0.025 \mathrm{~m}$ resolution was used to simulate flows corresponding to those in a physical scale model of a harbour of dimensions $1.0 \times 1.0 \times 0.25 \mathrm{~m}$ (Nash and Hartnett, 2014). In this way, the model allows improved accuracy of solution when compared to a lowerresolution parent model where the improved accuracy is similar to that of a similar high-resolution single-grid model, but the computational effort is significantly reduced.

Thirdly, the model provides adequate solutions at scales sufficient for processes of interest, such as coarse-resolution coastal circulation and fine-resolution flood inundation. This is attributed to the robust hydrodynamic module which in essence adopts the well-tested numerical scheme and discretization methods described by Falconer and Chen (1991). The uniqueness and improvement of MSN_Flood over other nested models are its formulation of the nested boundary in the area where flooding and drying may occur. In order to accommodate flooding and drying of boundary cells, the model allows a moving nested boundary so that large sections of the boundary can alternatively wet and dry. The stable flooding and drying of boundary cells result from the internalization of the nested boundary combined with an adaptive interpolation technique tailored specifically for this model. To the authors' knowledge the development of a non-continuous moving nested boundary in a circulation model is novel. Such an innovative solution does not pose restrictions on the location of nested grids with regards to wetting and drying (as demonstrated by the application to Cork Harbour) and, therefore, allows flexibility of model setup.

Finally, in the context of urban flood modelling, MSN_Flood's ability to simulate horizontal components of water velocity is a significant advantage over simpler hydraulic models commonly used in flood modelling; the complexity of urban topography (buildings, vegetation, walls, roads, embankments, ditches etc.) necessitates at least twodimensional treatment of surface flows (Cook and Merwade,
2009). Spatial and temporal distribution of velocity fields is also required for assessment of flood risk to people and property associated with a certain flood flow magnitude. Thus, this feature will greatly benefit flood hazard management.

Although the modelling framework seems to be the main factor controlling accuracy of model predictions, other factors such as model resolution, datasets and model parameterization also play a crucial role. In relation to model topography/bathymetry, these aspects are interconnected and need to be considered jointly. By comparing the 6 and $2 \mathrm{~m}$ grid models, it can be seen that results are quite sensitive to the spatial resolution of the model. The resolution acts as a filter on the model terrain so the model error increases with decreasing spatial resolution, as the definition of topographic features (walls, hedges etc.) are progressively lost from the model bathymetry. There is a dual effect of this. Firstly, as the resolution becomes less granular, the high-density small features of topography become sub-grid phenomena, which then become parameterized through roughness coefficients. Spatially varying roughness needs to be specified for different terrains; this is determined based on surface classification (such as land type, vegetation or roads) within model sensitivity and calibration. Secondly, the loss of larger objects such as buildings makes the model inherently ill-conditioned, and their loss cannot be remedied through modification of roughness coefficient alone. Errors are additionally amplified by a presence of bias in the topographic data resulting from lidar-related post-processing difficulties such as representation of surface objects as discussed in Mason et al. (2003).

\section{Conclusions}

In this research, high-resolution multi-scale modelling of coastal flooding due to tides, storm surges and rivers inflows is performed. The MSN_Flood modelling system is used to simulate flood water inundation of Cork city. The main findings from this research fall into two categories as follows:

1. Model computational performance:

a. The nesting model framework allows the model operation at practically any desired horizontal resolution, including scales commensurate with resolution of lidar data making optimal use of such datasets: in the current setup, a four-nest cascade telescopes resolution down to the level of lidar resolution, which is sufficient to capture small-scale flow features.

b. The model has no limits as to the number of nesting levels, and the numerical stability is maintained down to the finest resolution.

c. Computational effort is dictated by the number of nesting levels, the horizontal resolution of each nested grid and the extents of each nested grid. Nevertheless, at the finest resolution the nested model 
was found to be almost as accurate as a single-grid model of the same resolution but at a $96 \%$ savings in computational cost.

d. Due to its robust flooding and drying routine, the model maintains numerical stability and accuracy in any part of the model domain affected by these processes.

e. Internalization of the nested boundary through the use of ghost cells combined with a tailored adaptive interpolation technique permits flooding and drying of the nested boundary, creating highly dynamic moving boundaries. Moreover, the flooding and drying mechanism can approach the boundary of the nested domain from either upstream or downstream. Nesting with a moving boundary allows embedding of a child grid model within the parent model in areas where the nested boundary may wet or dry. This unique feature of MSN_Flood provides a high degree of choice regarding the location of the boundaries to the nested domain and therefore flexibility in model application. This capability gives MSN_Flood significant advantages over other models.

2. Model accuracy:

f. The modelling system demonstrates a good capability to accurately determine physical processes at different spatial scales, including mesoscale coastal water circulation $(90 \mathrm{~m})$ and small scale hydrodynamics of complex urban floodplains $(2 \mathrm{~m})$.

g. The extent of flood inundation into floodplains of Cork city and maximum water levels reached during flooding were accurately simulated by the urban flood $2 \mathrm{~m}$ grid model.

h. Fine horizontal resolution is crucial for accurate assessment of inundation. Comparison of 6 and $2 \mathrm{~m}$ grid model $\mathrm{RE}_{\mathrm{T}}$ in water levels shows a noticeable reduction in model performance at coarser resolution over the entire domain, and the error is generally greater in the dense street network of an urbanized zone.

i. The urban flood model provides full characteristics of water levels and flow regimes necessary for assessment of flood risk to people's safety associated with particular flood water levels and associated flood water velocities.

To conclude, near-unlimited model resolution, geographically unconstrained (due to wetting and drying) nested model setup, robust wetting and drying routine, computational efficiency and the capability to simulate both water elevations and velocity fields make the MSN_Flood a valuable tool for studying coastal flood inundation. This research demonstrates that the adopted methodology can be successfully used in applications to coastal flood modelling including complex urban environments. It can provide, at specific instances of time, accurate spatial distributions of water elevations and flow magnitudes in inundated areas and can, thus, provide critical information to assess possible extents of flood inundation, periods of inundation, maximum water elevations reached, and flood wave propagation routes and speeds. Ultimately, it can be directly used for evaluation of flood risks to the area and indirectly, through some functional relationships, for risk assessment of human safety and property damage. The methodology explored in this research, when applied in a forecasting sense, constitutes a high-resolution flood warning and planning system that can aid local decision makers targeting high-flood-risk areas.

\section{Data availability}

Data to develop this model were made available by the Irish OPW. These data may be made available from OPW on request from the corresponding author.

Acknowledgements. This publication has emanated from research conducted with the financial support of Science Foundation Ireland (SFI) under grant numbers SFI/12/RC/2302 and SFI/14/ADV/RC3021. The authors would like to thank OPW, Ireland for hydrological data and ECMWF for meteorological data. The authors would like to acknowledge the SFI/HEA Irish Centre for High-End Computing (ICHEC) for the provision of computational facilities and support. Useful suggestions from the two reviewers are appreciated.

Edited by: P. Tarolli

Reviewed by: two anonymous referees

\section{References}

Bates, P. D. and De Roo, A. P. J.: A simple raster-based model for flood inundation simulation, J. Hydrol., 236, 54-77, 2000.

Bates, P. D., Dawson, R. J., Hall, J. W., Horritt, M. S., Nicholls, R. J., Wicks, J., and Hassan, M. A. A. M.: Simplified twodimensional numerical modelling of coastal flooding and example applications, Coast. Eng., 52, 795-810, 2005.

Bates, P. D., Horritt, M. S., and Fewtrell, T. J.: A simple inertia formulation of the shallow water equations for efficient twodimensional flood inundation modelling, J. Hydrol., 387, 33-45, 2010.

Brown, J. D., Spencer, T., and Moeller, I.: Modeling storm surge flooding of an urban areas with particular reference to modelling uncertainties; A case study of Canvey Island, United Kingdom, Water Resour. Res., 43, W06402, doi:10.1029/2005WR004597, 2007.

Chen, X.: Dynamic coupling of a three-dimensional hydrodynamic model with a latterly averaged, two-dimensional hydrodynamic model, J. Geophys. Res., 112, C07022, doi:10.1029/2006JC003805, 2007. 
Cook, A. and Merwade, V.: Effect of topographic data, geometric configuration and modelling approach on flood inundation mapping, J. Hydrol., 377, 131-142, 2009.

DHI Software: Mike 21 flow model: hydrodynamic module user guide, DHI water and Environment, 2001.

Falconer, R. A.: A mathematical model study of the flushing characteristics of a shallow tidal bay, P. Civil. Eng. Pt. 2, 77, 311-332, 1984.

Falconer, R. A. and Chen, Y. P.: An improved representation of flooding and drying and wind stress effects in a 2-D tidal numerical model, P. Civil. Eng Pt. 2, 91, 659-678, 1991.

Fewtrell, T. J., Duncan, A., Sampson, C. C., Neal, J. C., and Bates, P. D.: Benchmarking urban flood models of varying complexity and scale using high resolution terrestrial LiDAR data, Phys. Chem. Earth, 36, 281-291, 2011.

Formaggia, L., Gerbeau, J. F., Nobile, F., and Quarteroni A.: On the coupling of 3D and 1D Navier-Stokes equations for flow problems in compliant vessels, Comput. Method. Appl. M., 191, 561582,2001

Gallegos, H. A., Schubert, J. E., and Sanders, B. F.: Twodimensional high-resolution modelling of urban dam-break flooding: A case study of Baldwin Hill, California, Adv. Water Resour., 32, 1323-1335, 2009.

Gomes-Pereira, L. M. and Wicherson, R. J.: Suitability of laser data for deriving geographical data: a case study in the context of management of fluvial zones, Photogrammetry and Remote Sensing, 54, 105-114, 1999.

Haidvogel, D. B., Arango, H., Budgell, W. P., Cornuelle, B. D., Curchitser, E., Di Lorenzo, E., Fennel, K., Geyer, W. R., Hermann, A. J., Lanerolle, L., Levin, J., McWilliams, J. C., Miller, A. J., Moore, A. M., Powell, T. M., Shchepetkin, A. F., Sherwood, C. R., Signell, R. P., Warner, J. C., and Wilkin, J.: Ocean forecasting in terrain-following coordinates: Formulation and skill assessment of the Regional Ocean Modeling System, J. Comp. Phys., 227, 3595-3624, 2008.

Halcrow: Lee catchment flood risk assessment and management study, Hydrology report, Halcrow Group Ireland Ltd., 2008.

Holt, J., Harle, K, Proctor, R., Michel, S., Ashworth, M., Batstone, C., Allem, I., Holems, R., Smyth T., Haines, K., Bretherton, D., and Smith G.: Modelling the global coastal ocean, Philos. T. R. Soc. A, 367, 939-951, 2009.

Horritt, M. S.: Calibration and validation of a 2-dimensional finite element flood flow model using satellite radar imaginary, Water Resour. Res., 36, 3279-3291, 2000.

Horritt, M. S., Bates, P. D., and Mattinson, M. J.: Effects of mesh resolution and topographic representation in 2D finite volume models of shallow water fluvial flow, J. Hydrol., 329, 306-314, 2006

Hunter, N. M., Bates, P. D., Neelz, S., Pender, G., Villanueva, I., Wright, N. G., Liang, D., Falconer, R. A., Lin, B., Waller, S., Crossley, A. J., and Mason, D. C.: Benchmarking 2D hydraulic models for urban flooding, Water Management, 161, 1330, 2008.

Kashefipour, S. M., Lin, B., Harris, E., and Falconer, R. A.: Hydroenvironmental modelling for bathing water compliance of an estuarine basin, Water Res., 36, 1854-1868, 2002.

Korres, G. and Lascaratos, A.: A one-way nested eddy resolving model of the Aegean and Levantine basins: implemen- tation and climatological runs, Ann. Geophys., 21, 205-220, doi:10.5194/angeo-21-205-2003, 2003.

Kvočka, D., Falconer, R. A., and Bray, M.: Appropriate model use for predicting elevations and inundation extent for extreme flood events, Nat. Hazards, 79, 1791-1808, 2015.

Lin, B. and Falconer, R. A.: Tidal flow and transport modelling using ULTIMATE QUICKEST scheme, J. Hydraul. Eng.-ASCE, 123, 303-314, 1997.

Mark, O., Weesakul, S., Apirumanekul, C., Aroonnet, S. B., and Djordjevic, S.: Potentials and limitations of 1D modelling of urban flooding, J. Hydrol., 299, 284-299, 2004.

Marks, K. and Bates, P. D.: Integration of high-resolution topographic data with floodplain flow models, Hydrol. Process., 14, 2109-2122, 2000.

Mason, D. C., Cobby, D. M., Horritt, M. S., and Bates, P. D.: Floodplain friction parameterization in two-dimensional river flood models using vegetation heights derived from airborne scanning altimetry, Hydrol. Process., 17, 1711-1732, 2003.

Mason, D. C., Horrit, M. S., Hunter, N. M., and Bates, P. D.: Use of fused airborne scanning laser altimetry and digital map data for urban flood modelling, Hydrol. Process., 21, 1436-1447, 2007.

McMillian, H. K. and Brasington, J.: Reduced complexity strategies for modelling urban floodplan inundation, Geomorphology, 90, 226-243, 2007.

Nash, S.: Development of an adaptive mesh inter-tidal circulation model, PhD Thesis, Collage of Engineering and Informatics, National University of Ireland, Galway, 2010.

Nash, S. and Hartnett, M.: nested circulation modelling of inter-tidal zones: details of nesting approach incorporating moving boundary, Ocean Dynam., 60, 1479-1495, 2010.

Nash, S. and Hartnett, M.: Development of a nested circulation model: boundary error reduction, Environ. Modell. Softw., 53, 65-80, 2014.

Nittis, K., Perivoliotis, L., Korrea G., Tziavos, C., and Thanos, I.: Operational monitoring and forecasting for marine environmental applications in the Aegean sea, Environ. Modell. Softw., 21, 243-257, 2006.

Olbert, A. I. and Hartnett, M.: Storms and surges in Irish coastal waters, Ocean Modell., 34, 50-62, 2010.

Olbert, A. I., Nash, S., Cunnane, C., and Hartnett, M.: Tide-surge interactions and their effects on total sea levels in Irish coastal waters, Ocean Dynam., 63, 599—614, 2013.

Olbert, A. I., Comer, J., Nash, S., and Hartnett, M.: High-resolution multi-scale modelling of coastal flooding due to tides, storm surges and river inflows. A Cork City example, Coast. Eng., 121, 278-296, doi:10.1016/j.coastaleng.2013.12.006, 2017.

Pappenberger, F., Beven, K., Horritt, M., and Blazkova, S.: Uncertainty in the calibration of effective roughness parameters in HEC-RAS using inundation and downstream level observations, J. Hydrol., 302, 46-69, 2005.

Pender, G. and Neelz, S.: Benchmarking of 2D hydraulic modelling packages. SC080035/R2 Environmental Agency, Bristol, p. 169, 2010.

Ponte, R. M.: Understanding the relation between wind- and pressure-driven sea level variability, J. Geophys. Res., 99, 80338039, 1994.

Robins, P. E., Davies, A. G., and Jones, R.: Application of coastal model to simulate present and future inundation and aid coastal management, J. Coast Conserv., 15, 1-14, 2011. 
Sanders, B. F., Schubert, J. E., and Detwiler, R. L.: ParBreZo: A parallel, unstructured grid, Godunov-type, Shallow water code for high-resolution flood inundation modelling at the regional scale, Adv. Water Resour., 33, 1456-1467, 2010.

Simmons, A. J., Burridge, D. M., Jarraud, M., Girard, C., and Wergen, W.: The ECMWF medium-range prediction models development of the numerical formulations and the impact of increased resolution, Meteorol. Atmos. Phys., 40, 28-60, 1989.

Smith, L. C.: Emerging applications of interferometric synthetic aperture radar (INSAR) in geomorphology and hydrology, Ann. Assoc. Am. Geogr., 92, 385-398, 2002.

Spall, M. A. and Holland, W. R.: A nested primitive equation model for oceanic applications, J. Phys. Oceanogr., 21, 205-220, 1991.

Uppala, S. M., Kallberg, P. M., Simmons, A. J., Andrae, U., Bechtold, V., Fiorino, M., Gibson, J., Haseler, J., Hernandez, A., Kelly, G., Li X., Onogi, K., Saarinen, S., Sokka, N., Allan, R., Andersson, E., Arpe, K., Balmaseda, M., Beljaars, A., Berg, L., Bidlot, J., Bormann, N., Caires, S., Dethof, A., Dragosavac, M., Fisher, M., Fuentes, M., Hagemann, S., Holm, E., Hoskins, B., Isaksen, L., Janssen, P., McNally, A., Mahfouf, J., Jenne, R., Morcrette, J., Rayner, N., Saunders, R., Simon, P., Sterl, A., Trenberth, K., Untch, A., Vasiljevic ,D., Viterbo, P., and Woollen, J.: The ERA40 reanalysis, Q. J. Roy. Meteor. Soc., 131, 2961-3012, 2005.
Yang, Z., Wang, T., Khangaonkar, T., and Breithaupt, S.: Integrated modelling of flood flows and tidal hydrodynamics over coastal floodplains, Environ. Fluid Mech., 12, 63-80, 2012.

Yu, D. and Lane, S. N.: Urban fluvial flood modelling using twodimensional diffusion-wave treatment: 1 . Mesh resolution effects, Hydrol. Process., 20, 1541-1565, 2006. 